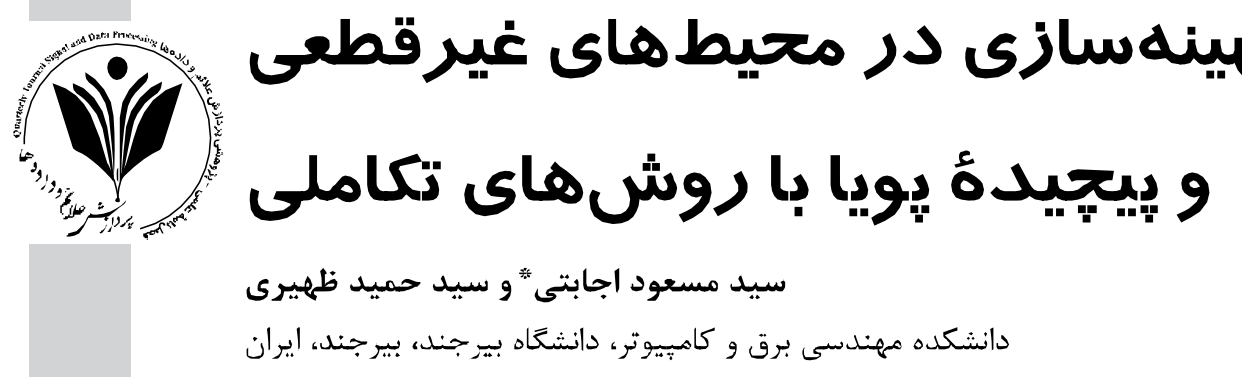

جكيده

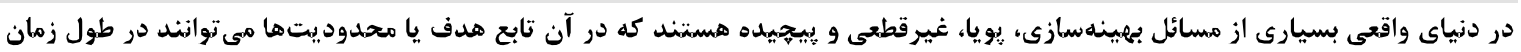

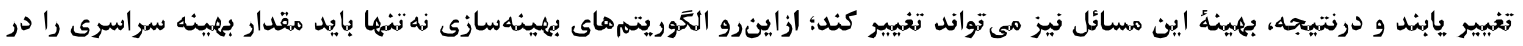

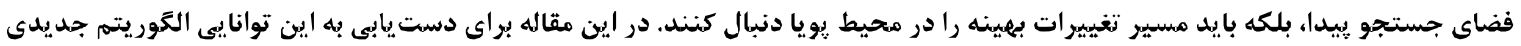

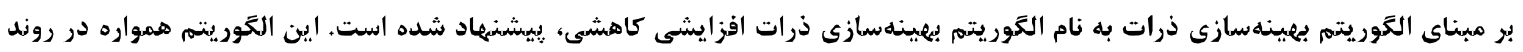

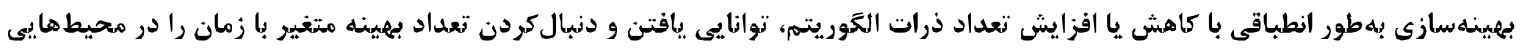

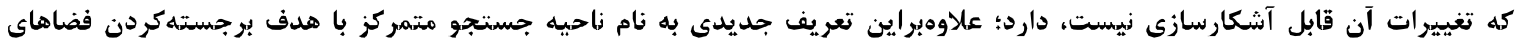

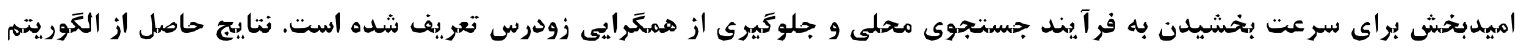

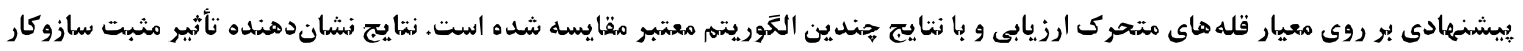

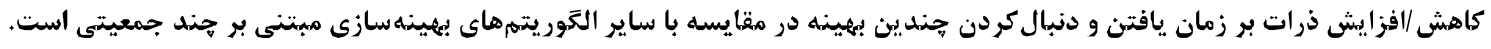

وازَّان كليدى: افزايش و كاهش ذرات، مسائل بهيينهازى يويا (DOPs)، روش جندجمعيتى، الكَّوريتم بعينهسازى ذرات

\title{
Optimization in Uncertain and Complex Dynamic Environments with Evolutionary Methods
}

\author{
Seyyed Masoud Ejabati" \& Seyed Hamid Zahiri
}

Electrical and Computer Faculty, University of Birjand, Birjand, Iran.

\section{Abstract}

In the real world, many of the optimization issues are dynamic, uncertain, and complex in which the objective function or constraints can be changed over time. Consequently, the optimum of these issues is changed nonlinearly. Therefore, the optimization algorithms not only should search the global optimum value in the space but also should follow the path of optimal change in dynamic environment. Accordingly, several researchers believe in the effectiveness of following a series of optimums compared to a global optimum. Therefore, when an environment is changed, following a global optimum in a series of best optimums is more efficient.

Evolutionary algorithms (EA) were inspired by biological and natural evolution. Because of changing characteristic of nature, it can be a good option for dynamic optimization. In recent years, different methods have been proposed to improve $\mathbf{E} \Lambda$ of static environments. One of the most common methods is multipopulation method. In this method, the whole space is divided into sub-spaces. Each sub-space covers some local optimums and represents a sub-population. The algorithm updates the particles of each sub-space and * Corresponding author

* *نويسنده عردهدار مكاتبات 
searches the best optimum. The most challenging issue of multi-population method is to create the desired number of sub-population and people to cover different sub-spaces in the search space.

In the present study, in order to deal with the challenges, a new algorithm based on particle optimization algorithm, which is called decrement and increment particle optimization algorithm, was proposed. The algorithm is able to follow and find the number of time-varied optimum in an environment with invisible changes by increasing or decreasing the number of particles adaptively.

Another challenging issue in dynamic optimization is the detection of environmental changes, due to the impossibility of this issue and failure of detection-based algorithms. In the proposed method, there is no need to detect the environmental changes and it always adapts itself to the environment.

Furthermore, the terms of focused search area were defined to emphasize on promising spaces to accelerate the local search process and prevent early convergence. The results of the proposed algorithm were evaluated on moving peaks and compared with several valid algorithms. The results showed the positive effect of decrement/increment mechanism of particles on finding and following time of many optimums compared to other multi-population based optimization algorithm.

Keywords: Increase decrease particle, Dynamic optimization problems (DOPs), Multi-population approach, Particle swarm optimization

از ميزان تغييرات در محيط، تغيير قسمتى از محيط و عدم

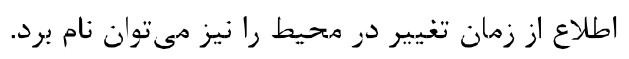

بهدليل آن كه الكوريتههاى تكاملمى بركرفته از تكامل

طبيعى يا بيولوزيكى هستند و طبيعت نيز همواره در حال

تغيير است، ازاينرو توانمندى خوبى براى استفاده در

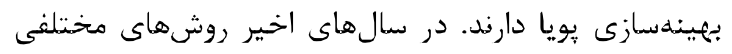

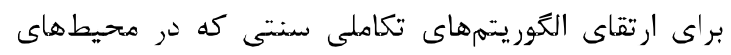

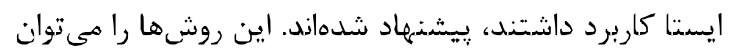
به ينج كروه دستهبندى كرث:

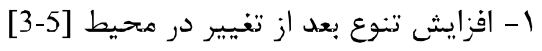

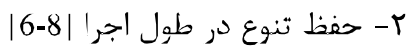
r- طرحهاى حافظه $[9,10$ f

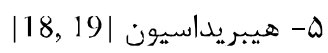

بسيارى از بزوهش گران بر اين عقيدهاند كه براى حل حل

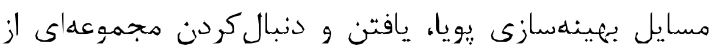

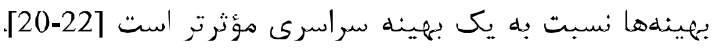

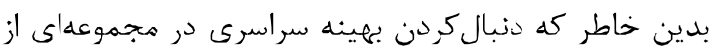

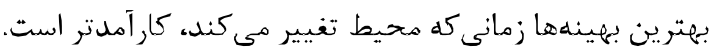

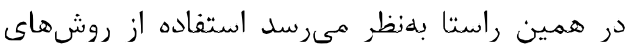

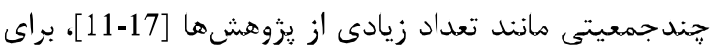
يافتن و دنبال كردن جندين بهينه محلى نزديك به به بهينه

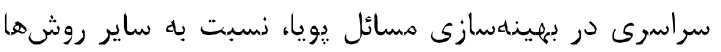

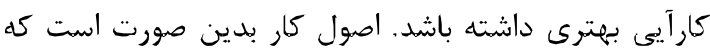
كل فضاى جستجو به زيرفضاهايى ج تقسيهم مى شود؛ هر زيرفضا بـاسي

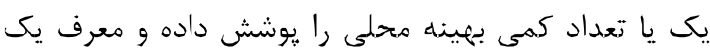

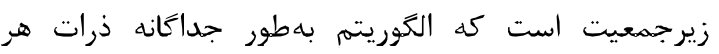

\footnotetext{
${ }^{8}$ Multi-population
}

${ }^{9}$ Sub-spaces

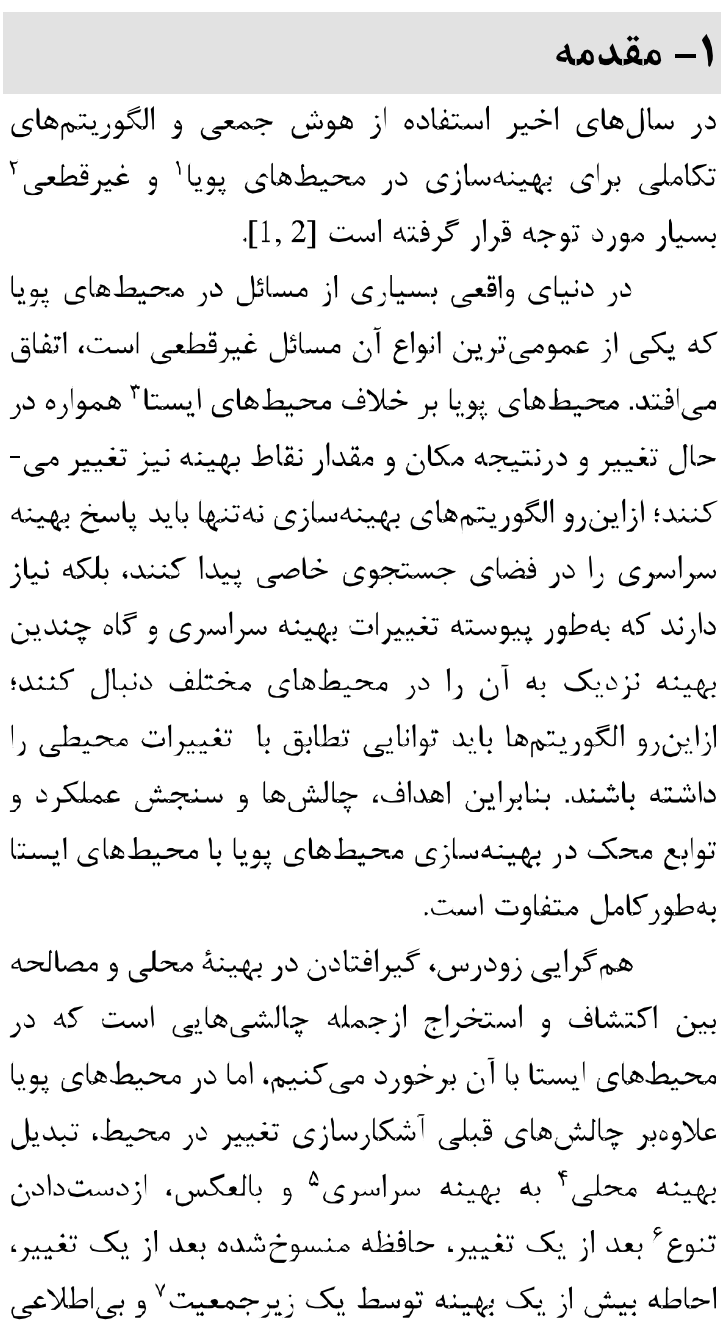

${ }^{1}$ Dynamic Environments

2 Uncertain

${ }^{3}$ Static Environments

${ }^{4}$ Local Optimum

5 Global optimum

${ }^{6}$ Diversity

${ }^{7}$ Sub-population 
سازماندهى اين هقاله به اين صورت است كه در بخش

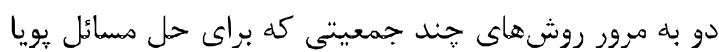

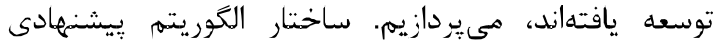
را در بخش سه بيان مى كنيم. بخش خهمار شامل نتايج

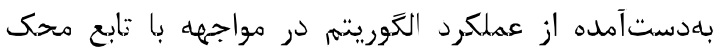
قلههاى متحرك با تنظيمهاى مختلف است و درنهايت مقاله با نتيجه گيرى و بحث در بخش بنج به بايان مىرسد.

\section{Y- روش هاى جندجمعيتى در محيطهاى :بو.يا}

در بهينهسازى محيطهاى يويا حفظ گَوناتونى جهعيت يكى از اساسىترين مسائل به شمار مىرود. در همين راستا بسيارى از يزوهشها در هواجهه با مسائل جندهدفهه نر هحيطهاى يويا نشان دادهاند كه براى حفظ گوناگونى جهعيت، رويكرد جندجمعيتى بسيار مؤثر است.

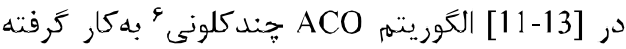
شده است كه در آن براى به بيشينهرساندن اكتشاف ل در كل

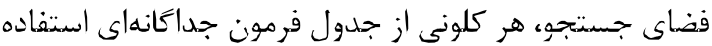

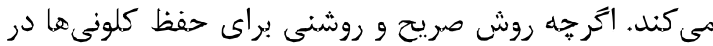

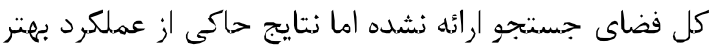

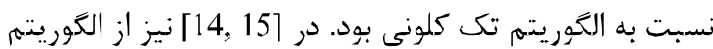
جند كلونى استفاده شده است با اين تفاوت كه جدول فرمون براى همه كلونى ها كه قبيله ناميده شدهاند، هشابه است

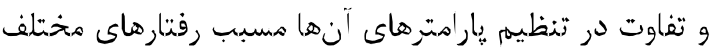
قبيلهها براى يوششدادن نواحى بيشترى از فضاى جستجو مىشود. مشابه جنين ايدهاى در PSO نيز به كار كرفته شده

است [16]

در [27] الحوريتم PSO جندجمعيتى بر اساس هدل جزيرهاى هعرفى شله است؛ بهطورىكه ذرات بهطور هنظهم بين جمعيتهاى مختلف مرهاجرت مى كنند. در [17] الكَوريتهم

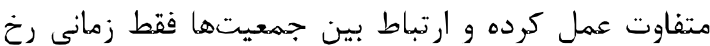
هى دهد كه تغيير در محيط مشاهده شون.

در يثوهش [28] كل جمعيت به دو دسته جمعيت

والدين كه موظف به جستجوى فضاى جستجو و جمعيت فرزندان كه موظف به دنبال كردن بهينهها هستند، تقسيم شدهاند. جمعيت والدين همواره در حال بررسى شرايط براى بـ برس

${ }^{5}$ Multi Modal

${ }^{6}$ Multi-colony $\mathrm{\Lambda CO}$

${ }^{7}$ Exploration

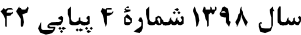

زيرجمعيت را بهروزرسانى كرده و به جستجوى بهينهُ بهتر

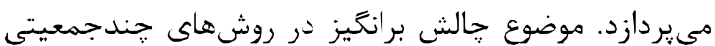

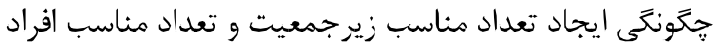
براى يوشثدادن زيرفضاهاى مختلف در فضاى جستجو است.

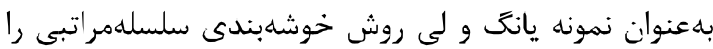
براى تقسيه خودكار فضاى جستجو به زيرجمعيتها بهكار كرفتهاند بسيارى از الكوريتمهاى بهينهسازى يويا بر مبناى آشكارسازى تغيير' در محيط شكل كرفتهاند و در آنها روشهايى براى آشكارسازى تغيير در هحيط استفاده شده دهيط است. آشكارسازى تغييرات در محيط كارى سخت و حتى در مواقعى مىتواند غيرممكن باشد. فرض كنيد كه فقط قسمتى از كل فضاى جستجو دستخوش تغيير شود، در اين حالت ييشبينى آن زيرفضا و يا آشكارسازى تغيير بسيار دشوار

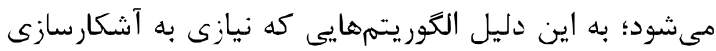

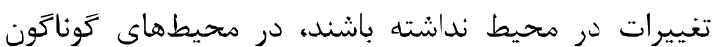
عملكرد بهترى از خود نشان مى دهند. در اين مقاله جهت استفاده مؤثر از روش جندجمعيتى در محيطهاى غيرقطعى و غيرقابل آشكارسازى، الكوريتم idPSOr

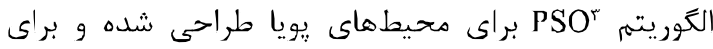
سرعتبخشيدن به روند بهينهسازى از سازوكار ساده و در عين

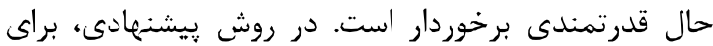

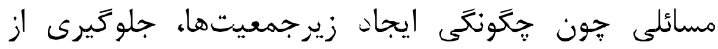

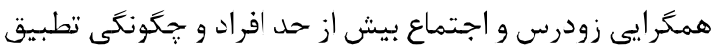
رفتار افراد با شرايط محيطى راه كارهاى نوينى ارائه شده است. همجنين تعاريف جديدى به نام ناحيه جستجوى متمركز و رون شعاع جستجو معرفى شده است. الخوريتم بيشنهادى بر روى تابع محك قلههاى

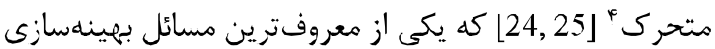
در محيطهاى يويا براى ارزيابى الكوريتمهاى بهينهسازى يويا

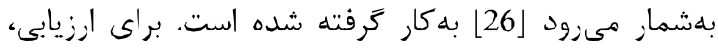

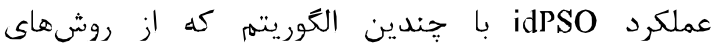
جندجمعيتى براى حل مسائل بهينهسازى يويا استفاده كردهاند، مقايسه و همهنين براى بررسى حساسيت الثوريتم

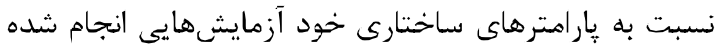

است.

\footnotetext{
1 Detect change

2 Increasing/Decreasing particle swarm optimization

3 Particle swarm optimization

${ }^{4}$ Moving peaks Benchmark (MPB)
} 
در يخوهشى ديخر، يك روش تطبيقى مبتنى بر

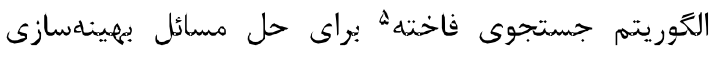

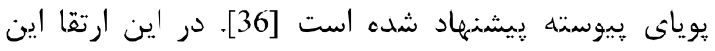

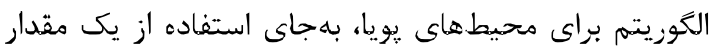

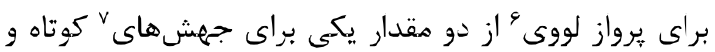

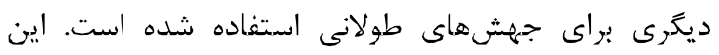

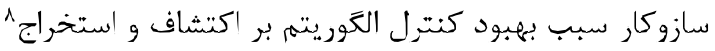
نقاط بهينه در طى روند جستجو مى شود. فولادكر و لطفى [37] ايدهائى ديخر به به الكَوريتم جستجوى فاخته براى بهينهسازى بويا اضافه كردهاند. رويكرد

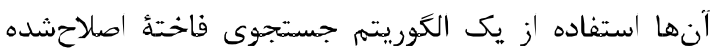

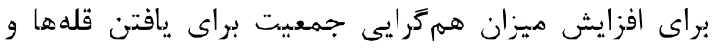

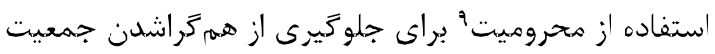
به مناطق مشابه در فضاى جستجو است.

\section{|-Y- محيطهاى يويـا بـا تغييـرات غيرقابـل تشخيص}

در بسيارى از بزوهشهايى [38] كه تاكنون براى حل هسائل

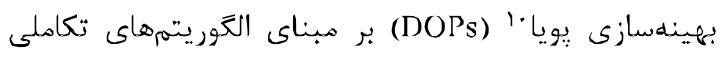

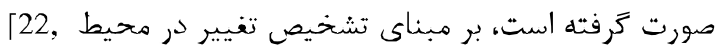

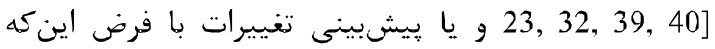
تغييرات از يك الكوى خواص تبعيت مي كنند [414]، توسعه يافتهاند. هنكامى كه تغييرات تشخيص داده شد و يا بيشيشينى

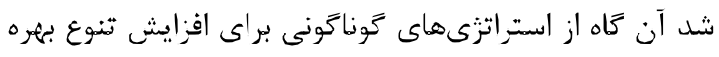

$$
\text { مى }
$$

با توجه به اهميت حفظ تنوع در حل هسائل بهينهاسازى يويا و وابستكى آن به تشخيص تغئ تغييرات محيط،

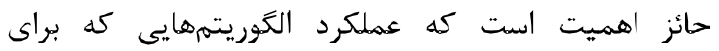
هحيطهاى بويا بيشنيهاد مىشود وابسته به شناسايى تغييرات

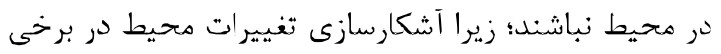

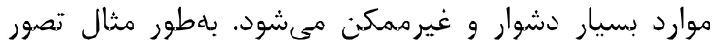

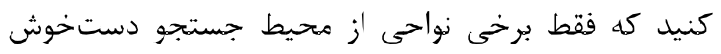

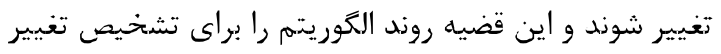

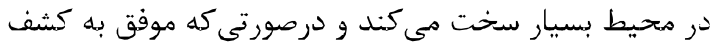

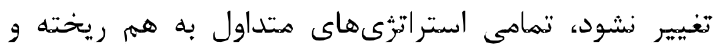

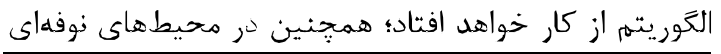

${ }^{5}$ Cuckoo search

${ }^{6}$ Tevy flight

${ }^{7}$ Mutation

${ }^{8}$ Exploitation

${ }^{9}$ Txclusion

${ }^{10}$ Dynamic optimization problems
ايجاد جمعيت كودكان هستند. كفتنى است كه تعداد كل افراد

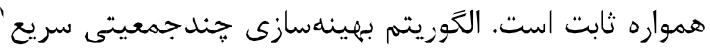
[29] با اين تفاوت كه جمعيت والدين بهعنوان جمعيت بايه

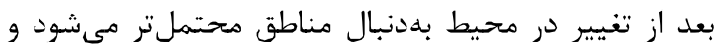

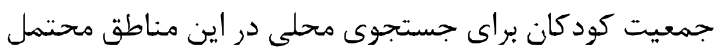

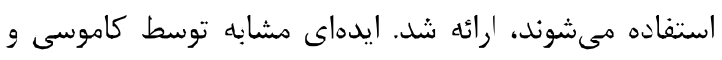

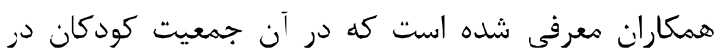

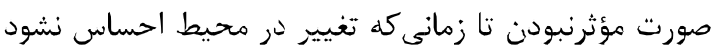
بهاصطلاح در خواب زهستانى مىروند [30].

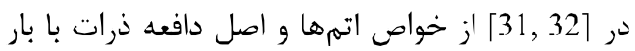
همنام براى حفظ تنوع در جمعيتها استفاده شده است. بدين

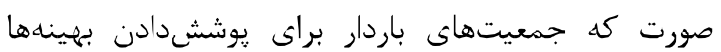

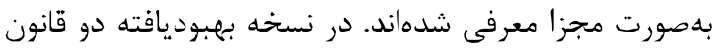

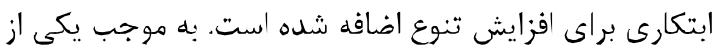

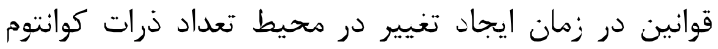

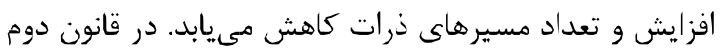

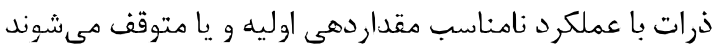

الكوريتم بهينهسازى ذرات خوشهاى بَّ توسط لى و يانگ

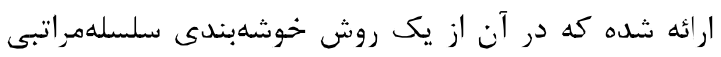

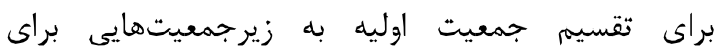

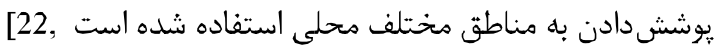

يزدانى و همكاران يك الكَريتم جندجمعيتى به نام linder-lracker multi-swarm PSO FTMPSO با استفاده از جندين سازوكار براى مقابله با بان

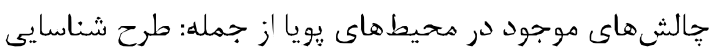

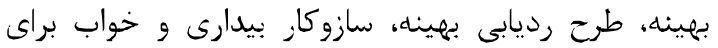

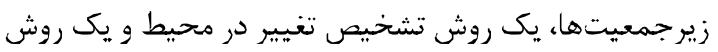

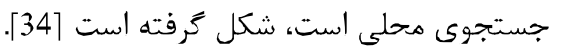

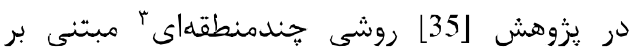

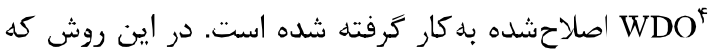

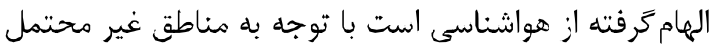

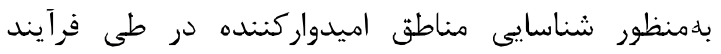

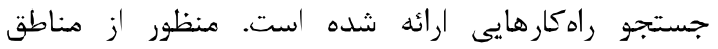

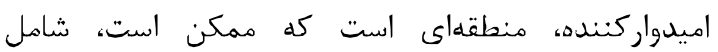
بهينههايى باشد كه هر يك از آنها بعاحتمال در محيط بعدى، به بهينه سراسرى مبدل شوند.

${ }^{1}$ Fast multi-swarm optimization (FMSO)

${ }^{2}$ Clustering PSO (CPSO)

${ }^{3}$ Multi-region

${ }^{4}$ Wind Driven Optimization 


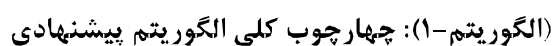

(Algorithm-1): The general framework of the porposed algorithm

\begin{tabular}{lc}
\hline Algorithm 1 idPSO I \\
\hline 1 & Initialize the free particles \\
2 & while stop criteria is not satisfied do \\
3 & for free particles do \\
4 & $P S O()$; \\
5 & end for \\
6 & convergenceChecking (free particles) \\
7 & if $F S Z$ exist then \\
8 & for each FSZ[i] do \\
9 & $P S O(F S Z[i])$ \\
10 & Update FSZ centers \\
11 & Check velocity of focus particles \\
12 & end for \\
13 & end if \\
14 & FSZoverlapChecking (FSZ,FSR) \\
15 & RemoveUselessFSZ \\
16 & end while \\
\hline
\end{tabular}

حلقه اصلى الخَوريتهم بيشنهرادى با مقداردهى اوليه براى

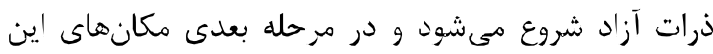

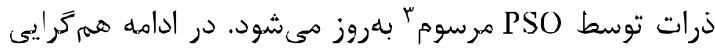

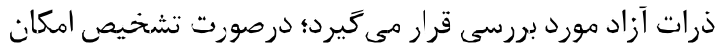
همم كرايى، ذراتى كه در ناحيه جستجوى متمركز

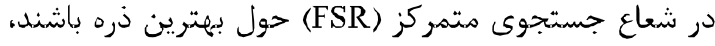

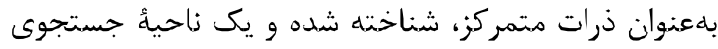

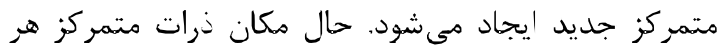

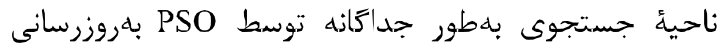

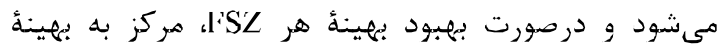

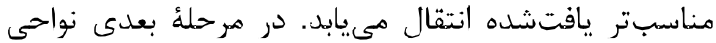
جستجوى هتمر كز از جهت روى همافتادكى بر رسى و در نهايت هايى كه بهينه خود را در اثر تغييرات شديد شرايط

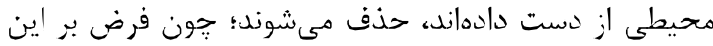

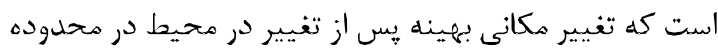

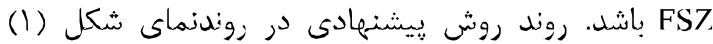
نمايش داده شده است. در الكَوريتم بيشنهيهادى ذرات به دو كَروه ذرات آزاد و

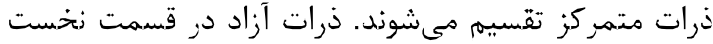

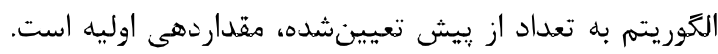

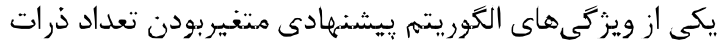

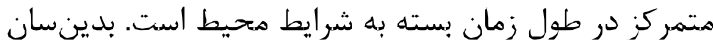
تعداد كل ذرات در طول اجراى الكوريتم همواره تابع شرايط

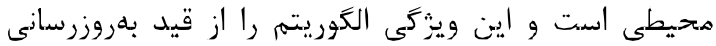

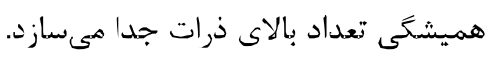

${ }^{3}$ Traditional
تشخيص تغيير براى اين دست از الكوريتمها، بسيار دشوار

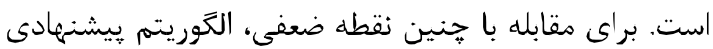

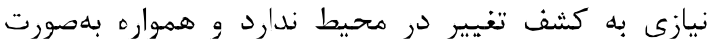
تطبيقى خود را با شرايط محيطى وقف مى دهد. در ادامه براى بهبود در حل هسائل بهينهسازى يويا و وديط غلبه بر كاستىهاى مرورشده در اين بخش، به توصيف روش يبشنهادى برداخته مىشود.

\section{r- الخَوريتم بهينه سازى ذرات افزاي ششى كاهشى}

در اين بخش الكوريتمه جديدى به نام Inceasing/Decreasing PSO براى بهينهسازى در محيطهاى يويا معرفى شده است بدئ براى همدامسازى PSO مرسوم براى محيطهاى يويا، ذرات به ديه دو كروه ذرات آزاد و ذرات متمركز تقسيم مىشونداي وظيفه ذرات آزاد جستجوى هميشكى در كل فضاى

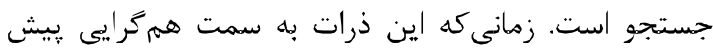
بروند تعدادى از آنها كه در محدوهاى به نام ناحيه جستجوى

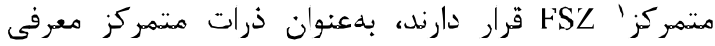
مى شوند. محدوده ناحيه جستجوى متمركز حول بهترين ذره

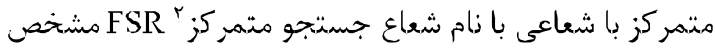

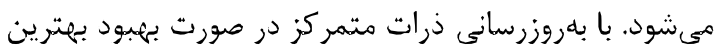
ذره، مركز FSZ نيز به مكان بهترين ذره متمركز تغيير بيدا مى كند و ساير ذرات متمركز اين ناحئ جستجو، ملزم به ديه

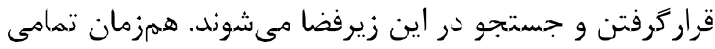
ذرات آزاد براى يافتن نقاط بهينه ديكر در فضاى جستجو يراكنده مىشوند. درواقع وظيفه ذرات آزاد جستجوى ابتدايى ديى

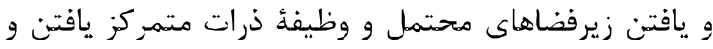

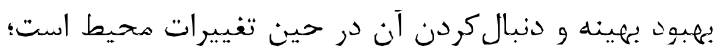
بدين صورت تعداد ذرات با توجه به ايجاد نواحى جستجوى اندي متمر كز و به تبع آن توليد ذرات متمركز جديد افزايش مى يابد. ساختار الكوريته بهكونهاى است كه هر زمان بسته به شرايط محيط بهينه مر:وط به هر ناحيه جستجوى متمركز از بين برود، كليه ذرات متمركز عضو آن ناحيه حذف مىشوند. بدين صورت همواره تعداد ذرات بهطور تطبيقى در حال تغيير است.

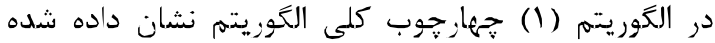

${ }^{1}$ Focused Search Zone

${ }^{2}$ Focused Scarch Radius 
مى كند. r و r r اعدادى تصادفى بين صفر و يك هستند. $c_{1}$ و

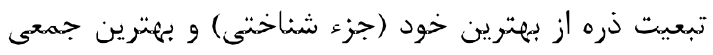

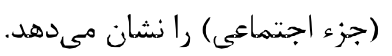

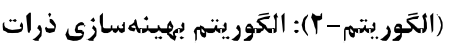

(Alyorithm-2): The process of PSO algorithm

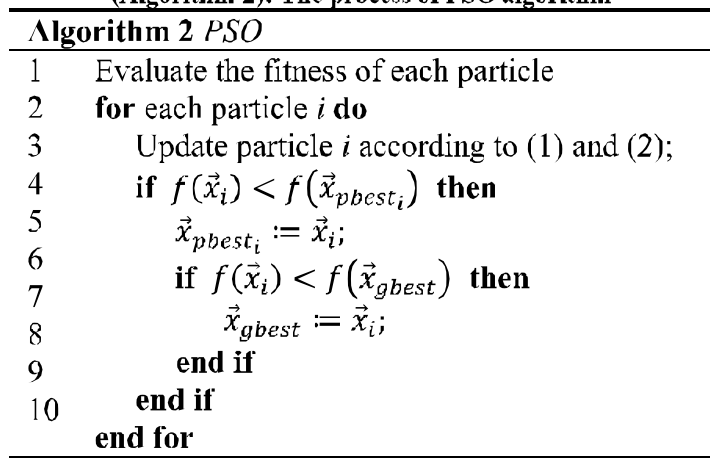

در كام بعدى حلقه اصلى الكوريتم بِيشنهادى، روند

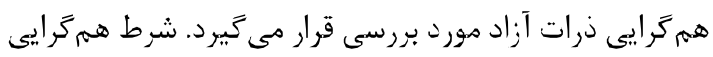

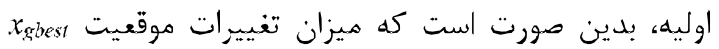
ذرات آزاد و برازندكى آن نسبت به مرحله قبل سنجيده

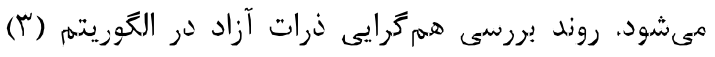
نمايش داده شده است. درصورتى كه تغييرات ماركار

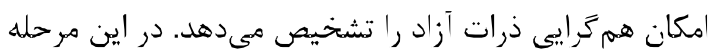

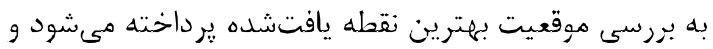

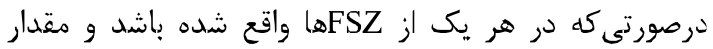

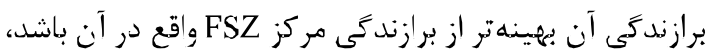

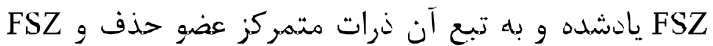

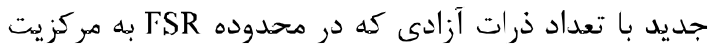

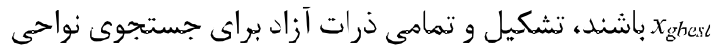

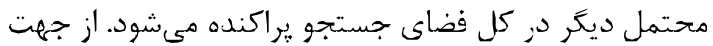

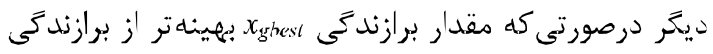
مركز FSZ واقع در آن نباشد، تماهى ذرات درات آزاد ير يراكنده

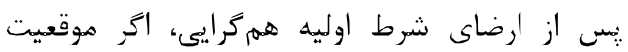

$$
\text { مىش شوند. }
$$

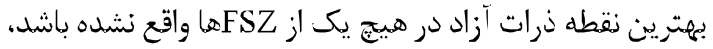

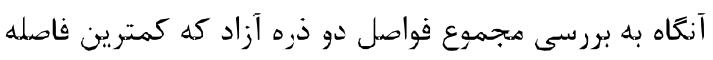

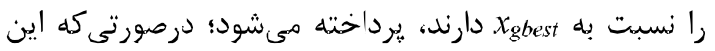

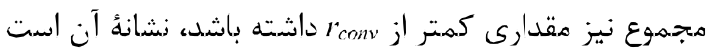

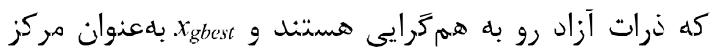

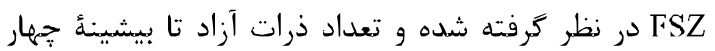

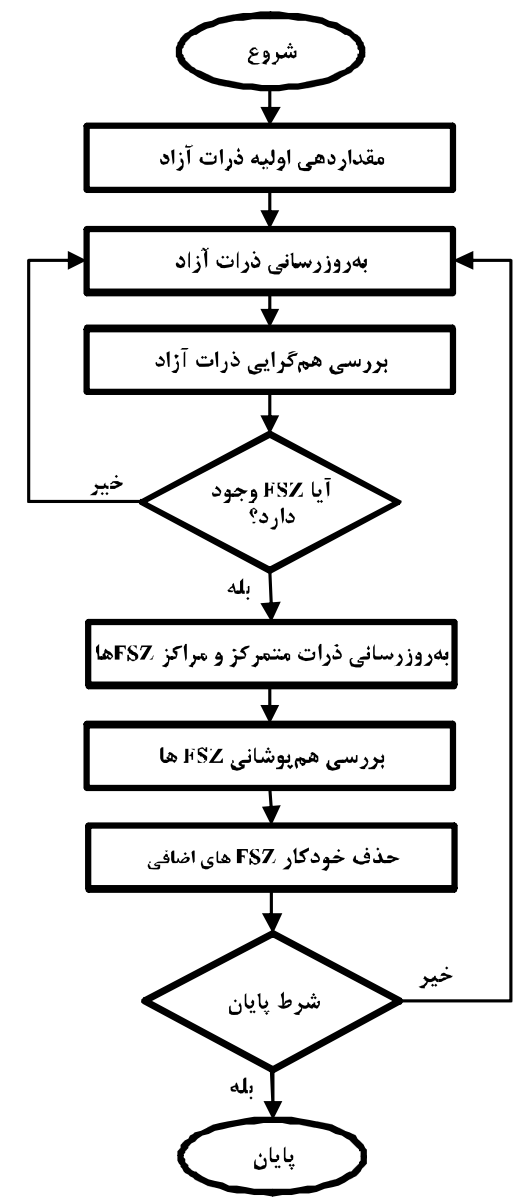

(شكل - (1): فلموجارت الكوريتهم بيشنههادى

(Figure -1): Flowchart Proposed Algorithm

در كام بعدى موقعيت ذرات آزاد توسط الكوريتم PSO

كه نخستينبار توسط كندى و ابرهارت يُبشنهاد شد [42,43]

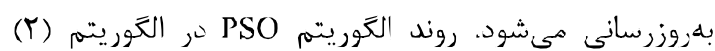
نشان داده شده است. هر ذره i با يك بردار سرعت

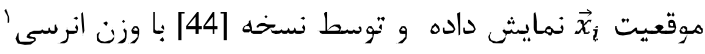
بلهورت زير بلروزرسانى مى نشود:

$$
\begin{aligned}
v_{i}^{\prime d}=\omega v_{i}^{d}+c_{1} r_{1}\left(x_{p b e s t_{i}}^{d}-x_{i}^{d}\right) & \\
& +c_{2} r_{2}\left(x_{\text {gbest }}^{d}-x_{i}^{d}\right)
\end{aligned}
$$

$x_{i}^{\prime d}=x_{i}^{d}+v_{i}^{\prime d}$

در رابطةٔ بالا سرعت كنونى و $v_{i}^{\prime d}$ بهن $\vec{x}_{\text {pbest }}^{d}$

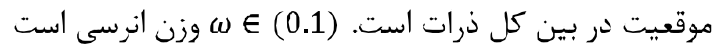
و ميزان تأثير سرعت قبلى در سرعت كنونى ذره رات العيين

${ }^{1}$ Inertia weight 


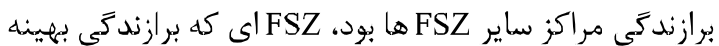

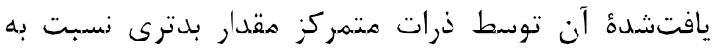
ديخرى داشت بهعنوان بهينه محلى تلقى شده و FSZ يادشده

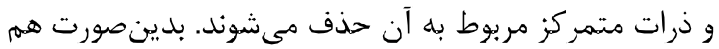
از جستجوى جند FSZ در يك ناحيه از فضاى جستجو

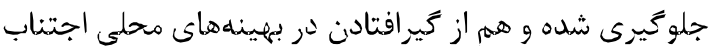

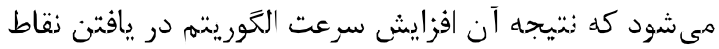
بهينه بيشتر در كل فضاى جستجو در زمان محدودترى است.

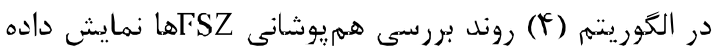

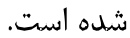

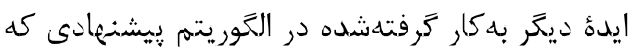

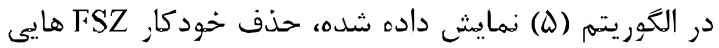
است كه يس از تغيبرات شديد لر محيط ديگر شاهد نقطه

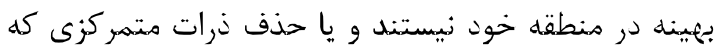

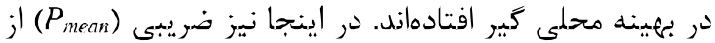
ميانگين برازندگى نقاط بهينة يافتشده بهعنوان معيار سنجش معرفى مى شود و در هر مرحله با مقايسه بدترين بهينه

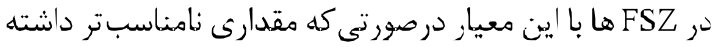

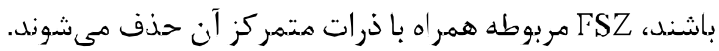

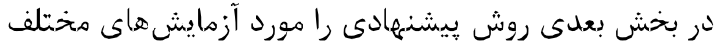

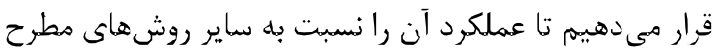

بسنججيمr.

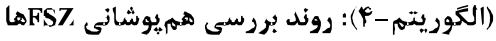

(Algorithm-4): The FSZ overlap checking process

\begin{tabular}{|c|c|}
\hline \multicolumn{2}{|c|}{ Algorithm 4 FSZoverlapChecking (FSZ,FSR) } \\
\hline 1 & if distance between $F S Z[i]$ center and \\
\hline 2 & $F S Z[j] \ldots$ center $<2 * F S R$ then \\
\hline 3 & $\int_{\text {mean }}\left(\right.$ center $\left._{I S Z}\right)$ - Calculation of mean \\
\hline 4 & fitness ... other centers \\
\hline 5 & if $f\left(\right.$ center $\left._{F S \angle[i]}\right)$ and $f\left(\right.$ center $\left._{F S \angle[j]}\right)$ beter \\
\hline 6 & than $\ldots P_{\text {mean }}{ }^{*} f_{\text {mean }}\left(\right.$ center $\left._{F S Z}\right)$ and $F S R>1$ \\
\hline 7 & then \\
\hline 8 & $F S R=($ distance between $F S Z[i]$ center \\
\hline 9 & and... FS $Z[j]$ center) $/ 2$ \\
\hline 10 & else \\
\hline 11 & delete $F S \%$ with worst fitness between \\
\hline 12 & $\ldots F S Z[i]$ and $F S Z[j\rfloor$ \\
\hline 13 & $\begin{array}{l}\text { end if } \\
\text { end if }\end{array}$ \\
\hline
\end{tabular}

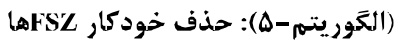

(Algorithm-5): The automatic removal of FSZs

\begin{tabular}{ll}
\hline Algorithm 5 Remove UselessFSZ \\
\hline 1 & $f_{\text {mean }}($ center $F S Z)=$ Calculation of mean all \\
2 & fitness... centers \\
3 & if worst $f\left(\right.$ center $\left._{F S Z}|i|\right)>f_{\text {mean }}\left(\right.$ center $\left._{F S Z}\right)$ then \\
4 & delete $F S Z$ with worst fitness $F S Z[i]$ \\
5 & end if
\end{tabular}

ذره كه در محدوده FSR نسبت به اين مركز باشند بهعنوان

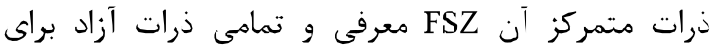
جستجوى مناطق محتمل ديگر در كل فضاى جستجو يراكنده

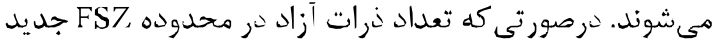

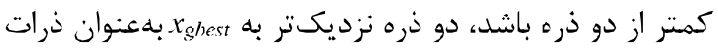
متمر كز براى FSZ يادشده يذيرفته ميى دوند دوند

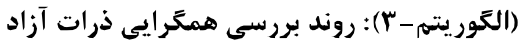

(Algorithm-3): The process of investigating free particle convergence

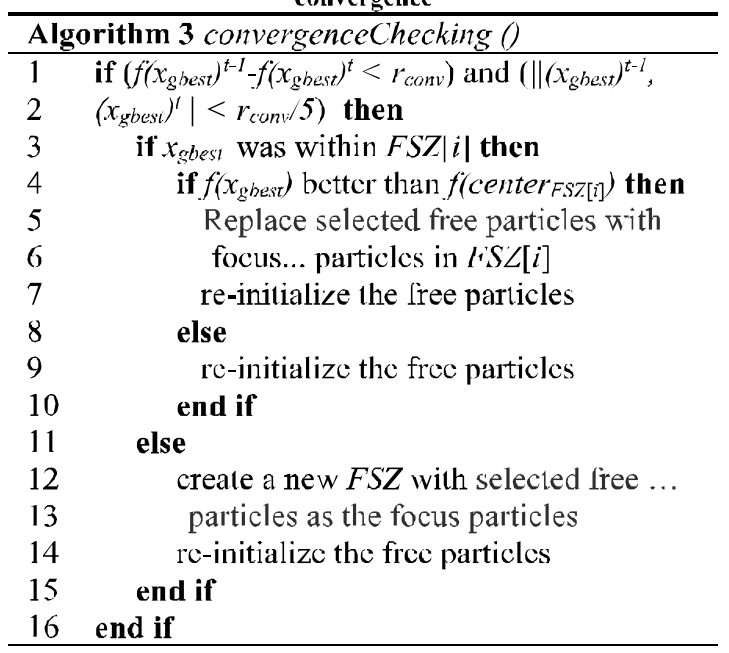

در گام بعدى موقعيت ذرات متمركز هر FSZ بهطور

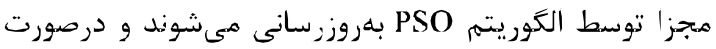

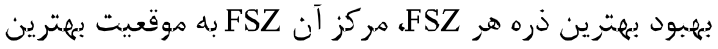

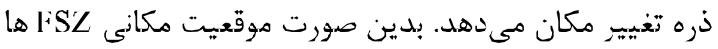

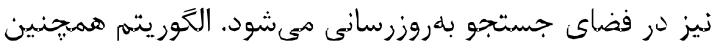

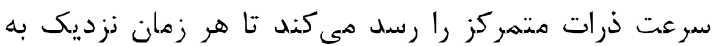
صفر شد، با براكنده كردن ذرات متمركز يادشده در محدوده

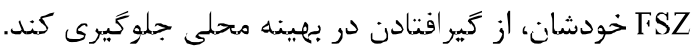
در الكَوريتم :بيشنهادى سازوكارى براى جلى جلوكيرى از

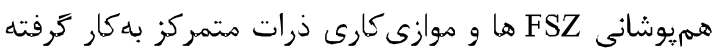
شده است. شر اين روش فواصل بين مراكز FSZ ها محاسبه

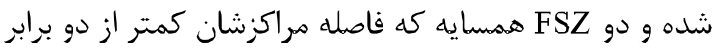

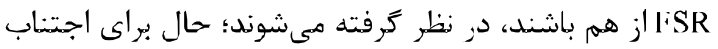

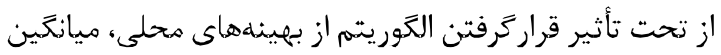

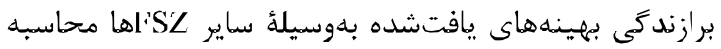

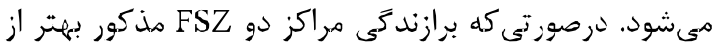

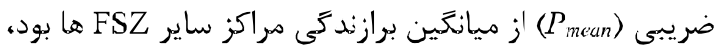

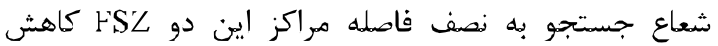
مىيابد تا هر دو بتوانند بهينه خود را دنبال كنند؛ حال اتر إن

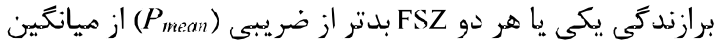


تابع max مخلوط مى شود. مكان قله در جهتى تصادفى توسط بردار

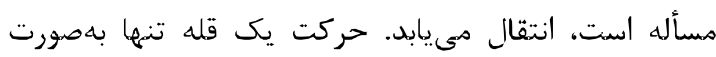

$$
\text { رابطه زير تعريف مىشود: }
$$

$\vec{v}_{i}(t)=\frac{s}{\left|\vec{r}+\vec{v}_{i}(t-1)\right|}\left((1-\lambda) \vec{r}+\lambda \vec{v}_{i}(t-1)\right)$

بردار انتقال (t)

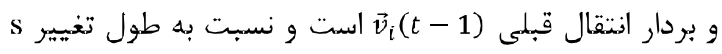

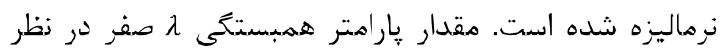

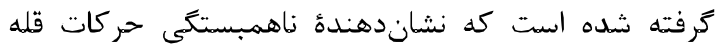

است. روابط تغييرات يك قلد بهصورت زير بيان مىشون:

$H_{i}(t)$

$=H_{i}(t-1)+$ height_severity

$\times \sigma$

$W_{i}(t)$

$=W_{i}(t-1)+$ width_severity

$\vec{X}_{i}(t)=\vec{X}_{i}(t)(t-1)+\vec{v}_{i}(t)$

كه در آن ه يك عدد تصادفى با توزيع نرمال و ميانگين صفر و واريانس يك است.

\section{r. تنظيمرهاى آزما بش:}

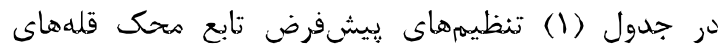

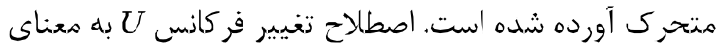

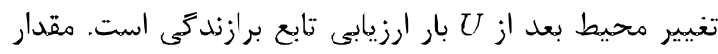
Peak location range هر بعد است. ارتفاع قله بهصورت تصادفى در بازه [30,70] و يهناى آن در بازه [1,12] تغيير مى كند.

MPB جدول-1): تنظيمهاى بيش فرض براى مسأله

(Table-1): Default setting for MPB

\begin{tabular}{|c|c|}
\hline Parameter & Value \\
\hline Number of peaks, $p$ & {$[1,200]$} \\
\hline Change frequency, $U$ & 5000 \\
\hline Height severity & 7.0 \\
\hline Width severity & 1.0 \\
Peak shape & Cone \\
\hline Basic function & No \\
\hline Shift length, $s$ & 1.0 \\
\hline Number of dimensions, $D$ & 5 \\
\hline Correlation coelficient, $\lambda$ & 0 \\
\hline Peaks location range & {$[0,100]$} \\
\hline Peak height, $I$ & {$[30,70]$} \\
\hline Peak width, $W$ & {$[1,12]$} \\
\hline Initial valuc of peaks & 50.0 \\
\hline
\end{tabular}

${ }^{1}$ Shift length f- أنتايج شبيهسازى

در اين بخش الكَوريتم بهينهسازى ذرات افزايشى كاهشى براى حل مسأله MPB بهكار كرفته شده است [24, 25]. آزمايشهاى انجامشله را مى توان به دو قسمت تقسيم كرد. هدف از قسمت نخست بروسى سازوكار idPSO و

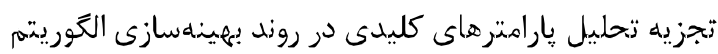

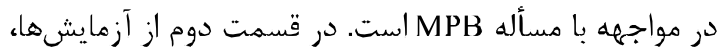

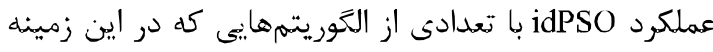

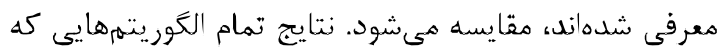

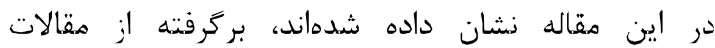
بيشنهيادشان است.

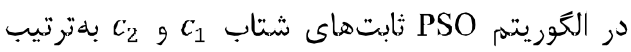
ميزان تبعيت ذره از بهترين خود (جزء شناختى) و بهترين

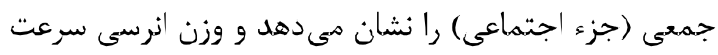

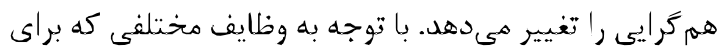

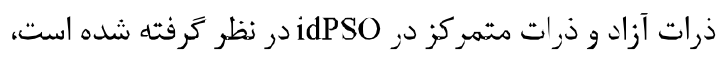

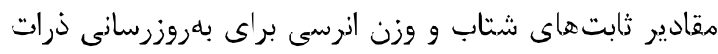

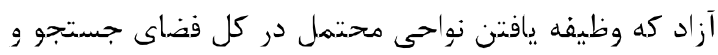

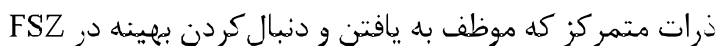
خودشان هستند، هتفاوت در نظر گرفته شده است. هقادير

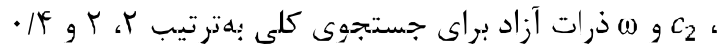

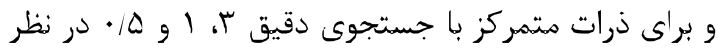
كرفته شده است.

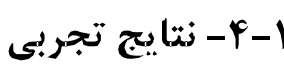
:Moving Peaks Benchmark (MPB) Problem .1 تابع هحك قلههاى متحرك يكى از معروفترين مسائل

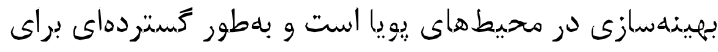

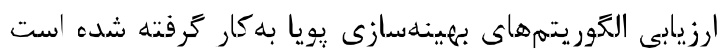

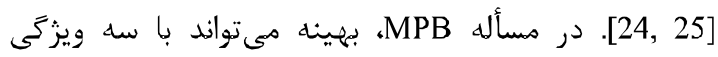

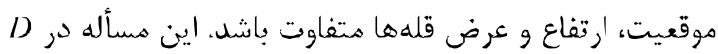

$$
\text { بعد بهصورت زير تعريف مىشود: }
$$

$F(\vec{x} . t)=\max _{i=1 \ldots . p} \frac{H_{i}(t)}{1+W_{i}(l) \sum_{j=1}^{j}\left(x_{j}(l)-X_{i j}(l)\right)^{2}}$

در رابطة (r) (r)

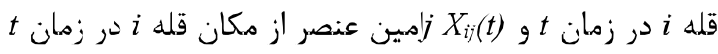
است. ياراهتر 


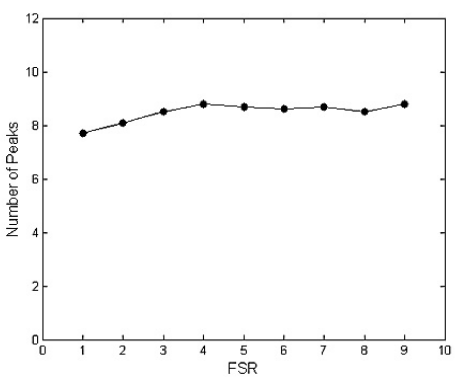

(ج)

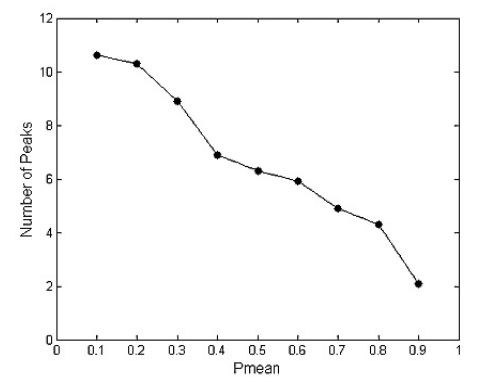

(ب)

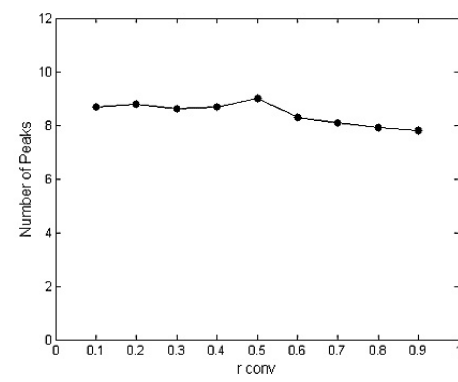

(الف)

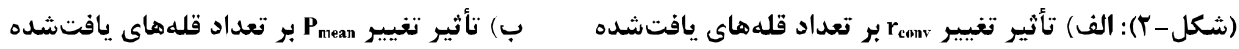

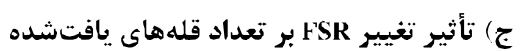

(Figure-2): (a) The effect of $r_{c o w}$ change on the number of peaks found (b) The effect of $p_{\text {mean }}$ change on the number of peaks found (c) The effect of the FSR change on the number of peaks found

شده است. در شكل (Y) تاثير تغييرات يارامترها بر روى تعداد قلههاى يافت شده، آمده است.

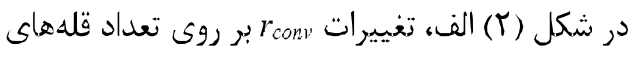

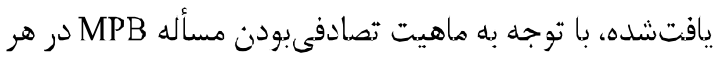

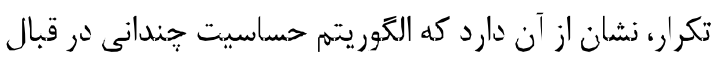
تغيير زمان انتقال وظيفه جستجوى نواحى محتمل و نقطه بهينه از

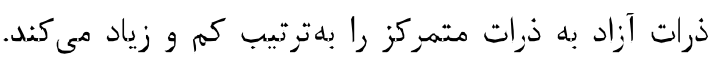

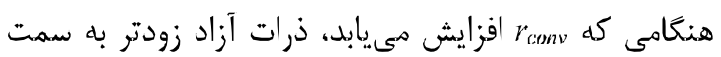

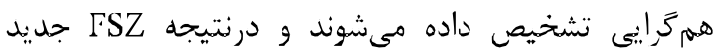

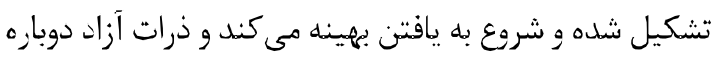
به وظيفه اصلى خود يعنى يافتن نواحى محتمل بر ميى شئوند.

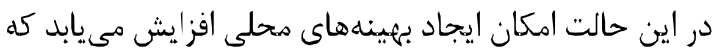

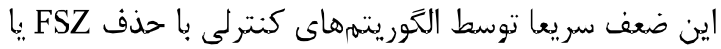

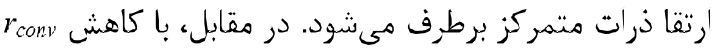
در واقع ذرات آزاد علاوهبر جستجوى نواحى محتمل، تا حد ند زيادى محكوم به يافتن مقدار بهينه كه جزو وظايف ذرات

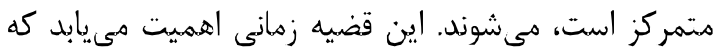

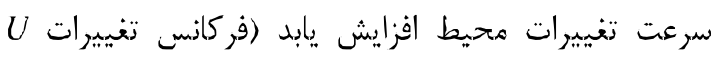
كاهش يابد). در اينجا بهدليل توانايى الخوريته تغيييرات

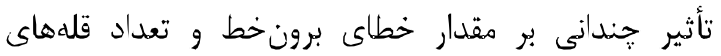

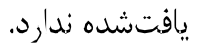

در شكل (T) ب نيز مشابه آنجِه در تغييرات مىافتد، با افزايش مقدار زمان بيشترى صورت مى كيرد و تا يافتن قله به تأخير مى افتند.

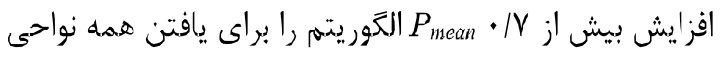

ب اندازمتيرى عملكرد:

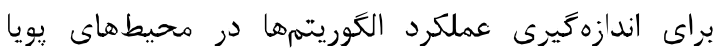

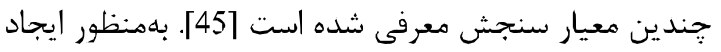

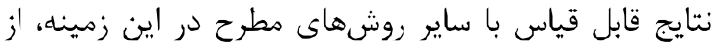

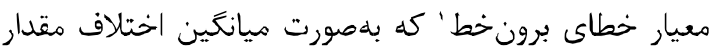

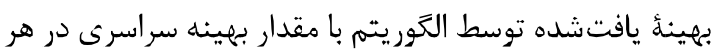
محيط تعريف مىشون، استفاهه شده است.

$O E=\frac{1}{K} \sum_{k=1}^{K}\left(h_{k}-f_{k}\right)$

دز رابطه بالا زf بهترين جواب يافتشده توسط الكوريتم تا قبل

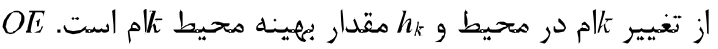

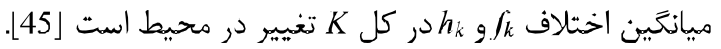

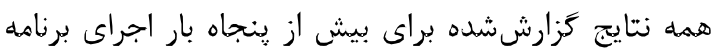
براى يكصد تغيير در محيط است.

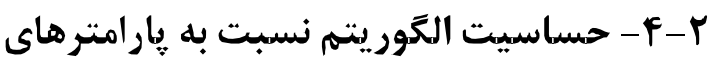 ساختارى}

roonv بهنظور بررسى حساسيت الكوريتم نسبت به يارارامترهاي

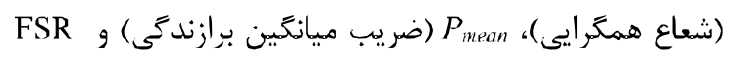

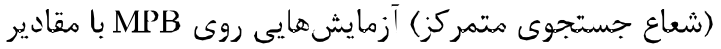
بيشفرض ( بيش بهدليل آن كه مقدار خطاى برون خط بهازاى تغييرات هارامتر در فركانس تغييرات هِنجهزار، بهطورتقريبى برابر و ونان

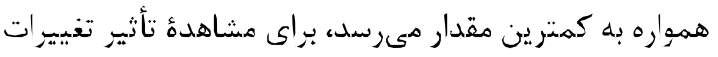

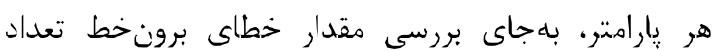

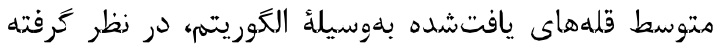

${ }^{1}$ Offline error $(\mathrm{OE})$ 
براى ايجاد FSZ ها و بهبود بهينه ها توسط ذرات متمركز جديد مىشوند و اين به معنى بار محاسباتى اضافه و صرف زمان بينتر براى بهينهسازى است.

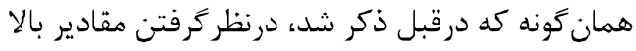

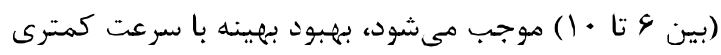

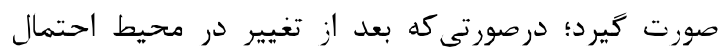

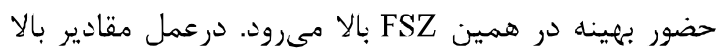

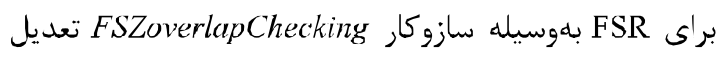

شده و به مقادير متوسط كاهش مى يابد.

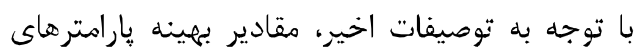

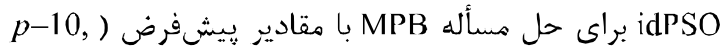
( U-5000,s-1 در جدول (r) آورده شده است.

(جدول - Y): تنظيمهاى idPSO براى حل مسأله MPB بيش فرض (Table-2): idPSO settings for solving the default MPB problem

\begin{tabular}{|c|c|}
\hline Parameter & Value \\
\hline Number of Free Particles & 20 \\
\hline$r_{\text {conv }}$ & 0.5 \\
\hline$P_{\text {mean }}$ & 0.3 \\
\hline FSR & 4 \\
\hline
\end{tabular}

شكل (Y) بلمنظور تجسم رفتار ذرات در مراحل

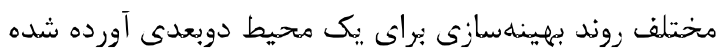

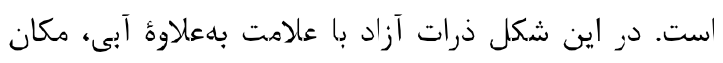

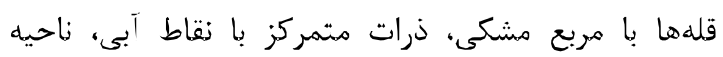

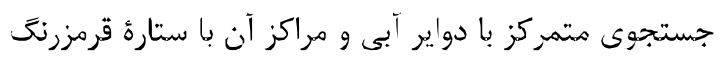
مشخص شدهاند. روند بهينهسازى از (الف) تا (و) نشان مى نهد كه

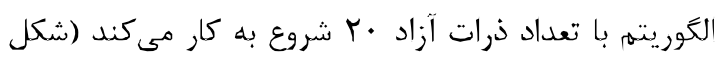

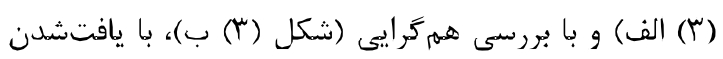

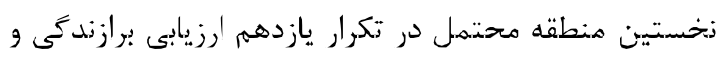

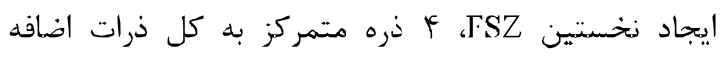

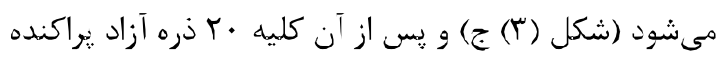

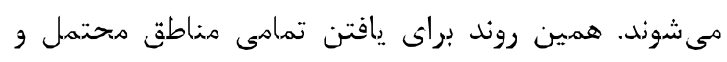

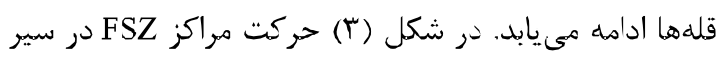

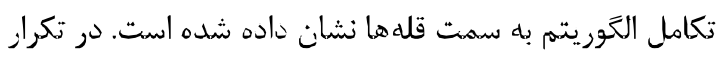

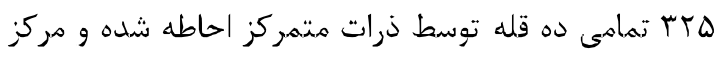

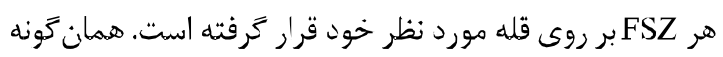

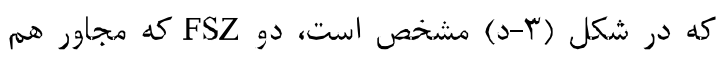

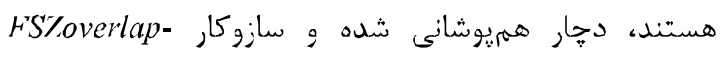

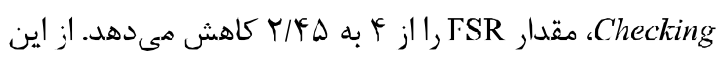

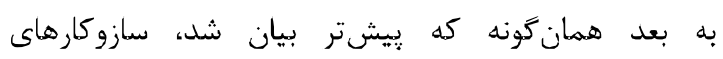
هازئ RemoveUselessFSZ g convergenceChecking
محتمل و درواقع همه قلهها مختل مي كند؛ زيرا در صورتى كه

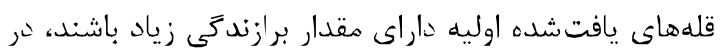

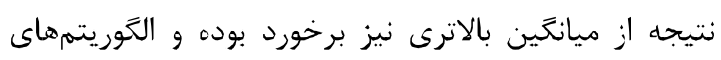

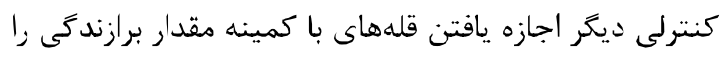

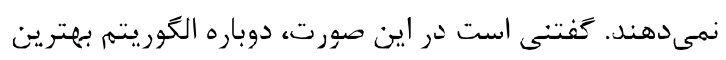

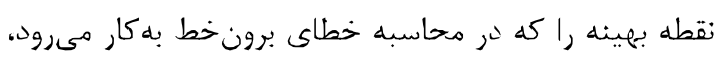

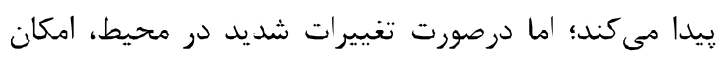

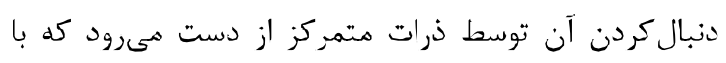

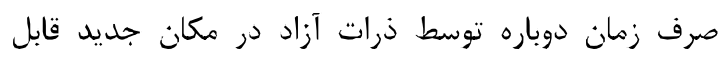

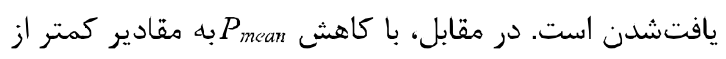

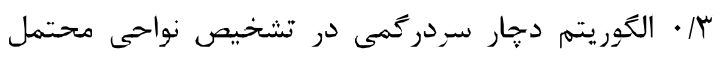
واقعى از محلى مى شود و بهطور معمول تعداد

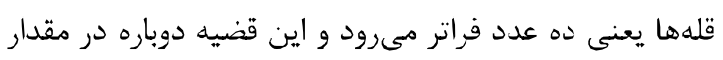

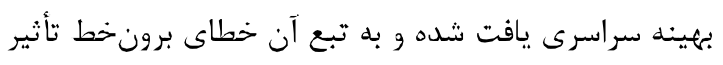

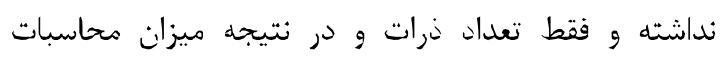
الكوريتم را بى مورد افزايش مى نهد.

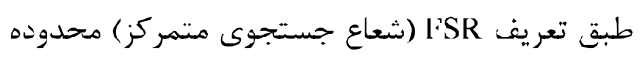
ناحيه جستجوى متمركز حول بهترين ذره متمركز آن ناحيه

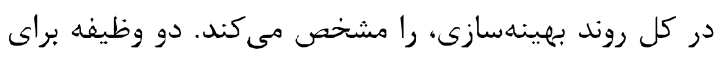

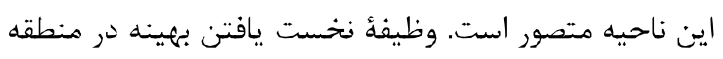

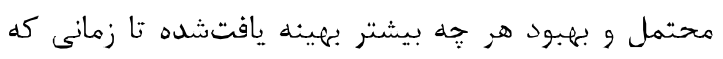

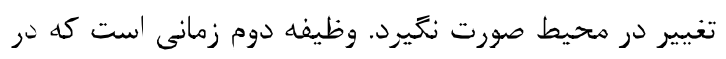

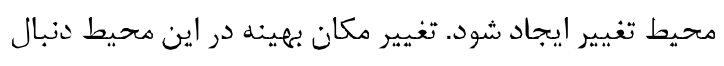

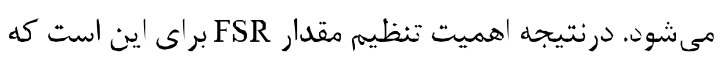

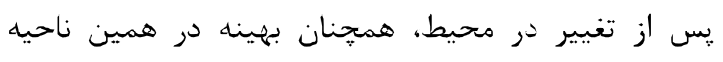

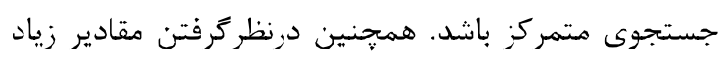

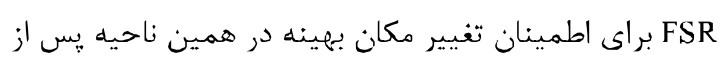

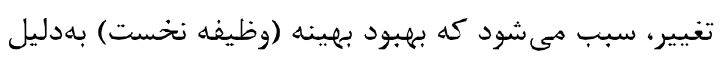

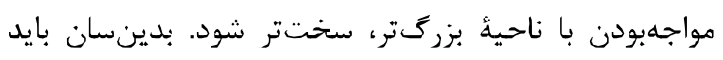

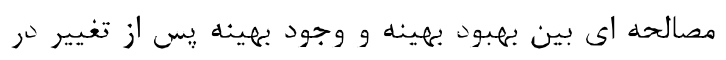

$$
\text { ناحيه برقرار شود. }
$$

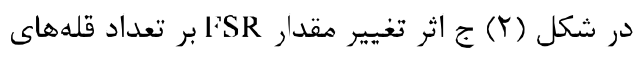

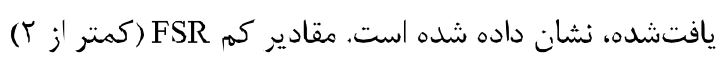

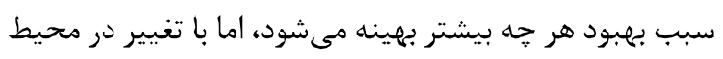

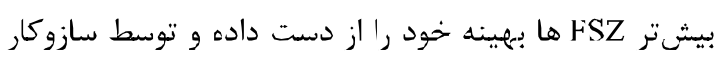
RemoveUselessFSZ

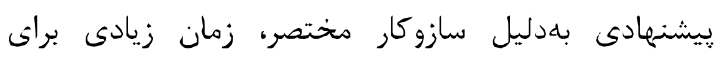

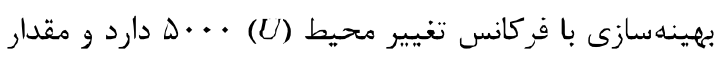

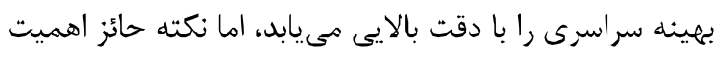

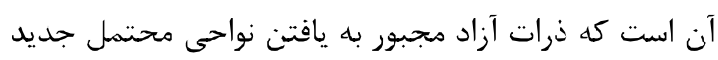


افز ايش تعداد ذرات، سير تكامل را طى كرده و كليه مقادير

ايجاد FSZ هاى جديد را تا تغيير در شرايط محيطى و يا

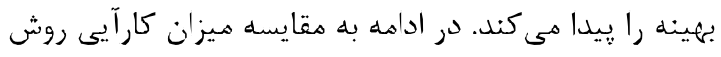
اضافهشدن قله نمى دهند.

$$
\text { ييشنهادى با ساير روشها يرداخته مىشون. }
$$

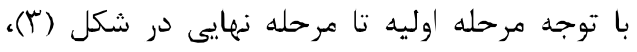

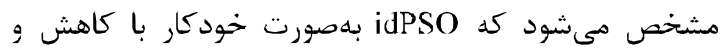

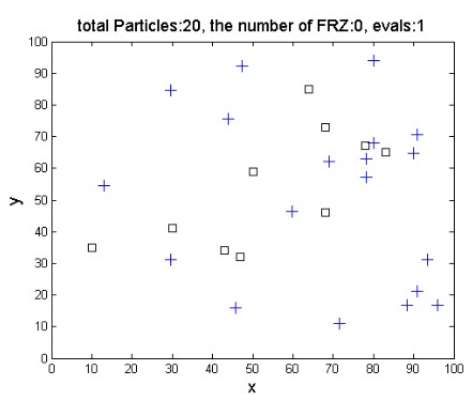

(ج)

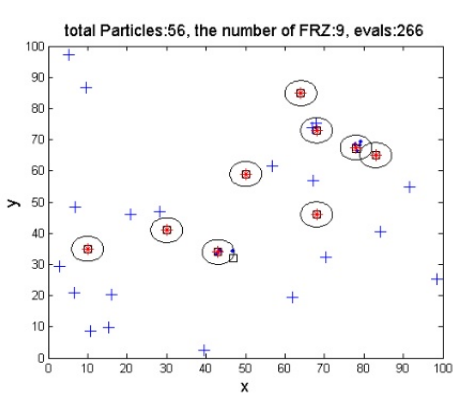

(g)

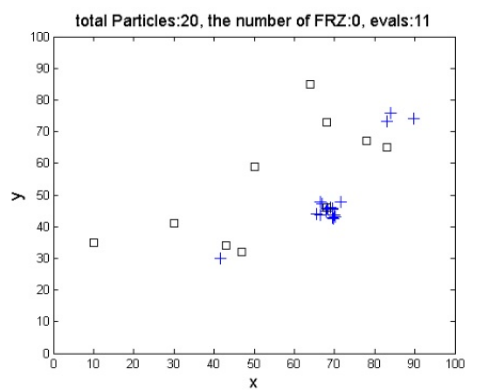

(ب)

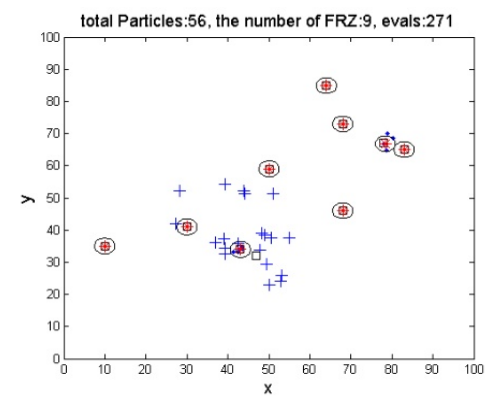

(०)

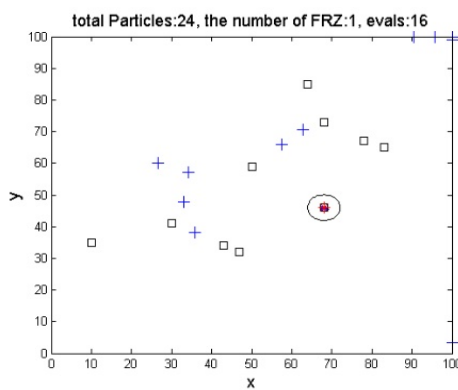

(الف)

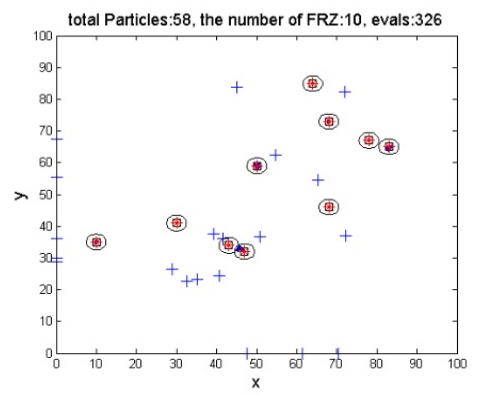

(১)

(شكل -r) : روند يافتن مناطق محتمل توسط ذرات آزاد و قله ها توسط ذرات متمركز در يك محيط دوبعدى

(Figure-3): The process of locating probable areas by free particles and peaks by focus particles in a two-dimensional environment

$$
\text { تنظيمهاى بهينه است، صورت كرفته است. }
$$

با توجه به جدول (ب)، نتايج براى الكوريته پِيشنهادى

براى بيشتر تعداد قلهها بهتر از ساير الكوريتمها در زمينه

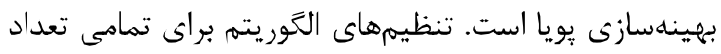

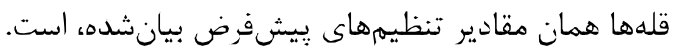
با دقت در مقادير خطاى برونخط idPSO و ساير الكوريتمها در جدول (T) متوجه مىشويم كه با افزايش تعداد

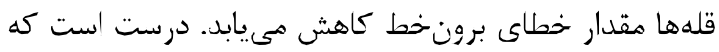

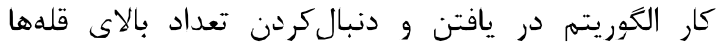

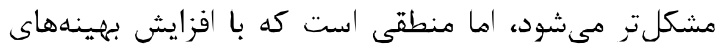

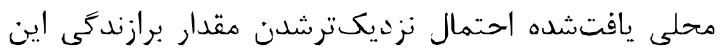

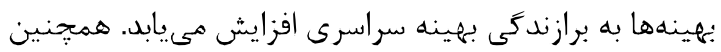
مناطق بيش ترى در فضاى جستجو توسط ذرات متمركز تحت

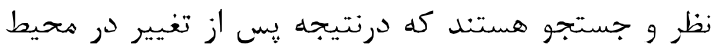

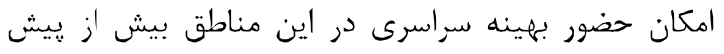
افزايش مى يابد.
r-F - مقايسه idPSO با الگوريتهمهاى ديگر

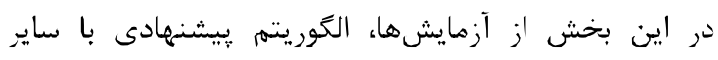

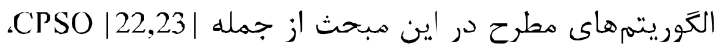
،rSPSO [46] cCESO [45] ،mQSO [32] ،mCPSO [32] .APSO [49] mPSO [48] ، AmQSO [47] ،SPSO [21] CDEPSO .PSO-AQ [51| SSFA [50| ،FTMPSO [34| , BfCS-wVN [36] ،WD2O [35]، CbDE-wCA [53]،52] cGA |54] در حل مسأله MPB با تنظيمهاى هختلف مقايسه شده است. در ادامه نتايج يزوهش تغيير تعداد قلهها، شدت

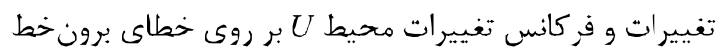

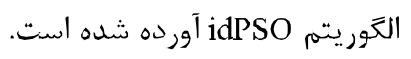

\section{1. - تغيير تعداد قلهها:}

در مجموعه آزمايشهايى كه در جدول (rاد) جمعآورى شده

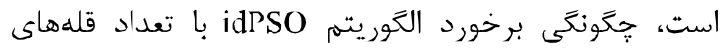
متفاوت در بازه يك تا دويست براى مسأله MPB نمايش داد داده شده است. مقايسه بر مبناى خطاى برون خط و وانحراف معاف معيار

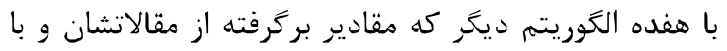


مكان بهينه به فاصله دورتر جابهجا مىشود. اين قضيه كار

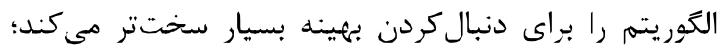

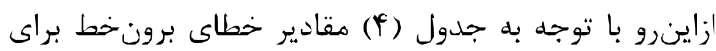

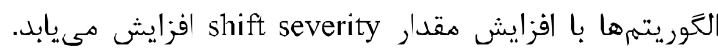

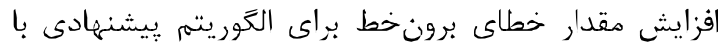

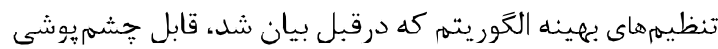

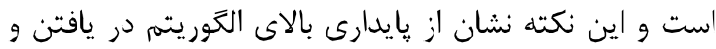

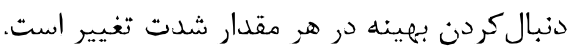

r.تغيير حساسيت يويايى محيط (شدت تغيير/ت):'

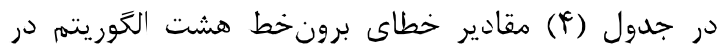
مقايسه با الكوريتم idPSO براى جهار شدت تغيدير مختلف

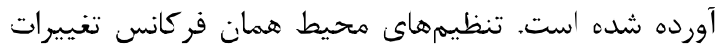

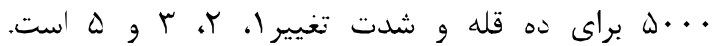

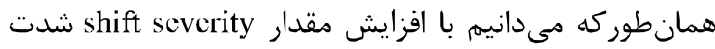
تغييرات در محيط افزايش مى يابد؛ بهعبارت ديكر هر هُ جه مقدار shift severity

U = 5000 (جدول - Y): مقايسه خطاى آفلاين الكوريتمها براى تعداد قله هاى متفاوت در مسأله فر كانس تغييرات (Table-3): Comparison of offline error algorithms for different peak numbers in the MPB problem at the change frequency of $U=5000$

\begin{tabular}{|c|c|c|c|c|c|c|c|c|}
\hline \multirow{2}{*}{ Algorithm } & \multicolumn{7}{|c|}{ Number of peaks, $\boldsymbol{p}$} \\
\cline { 2 - 9 } & $\mathbf{1}$ & 5 & 10 & 20 & 30 & 50 & 100 & 200 \\
\hline CPSO & $0.14(0.11)$ & $0.72(0.30)$ & $1.06(0.24)$ & $1.59(0.22)$ & $1.58(0.17)$ & $1.54(0.12)$ & $1.41(0.08)$ & $1.24(0.06)$ \\
\hline mCPSO & $4.93(0.17)$ & $2.07(0.08)$ & $2.08(0.07)$ & $2.64(0.07)$ & $2.63(0.08)$ & $2.65(0.06)$ & $2.49(0.04)$ & $2.44(0.04)$ \\
\hline mQSO(5,5q) & $2.24(0.05)$ & $1.82(0.08)$ & $1.85(0.08)$ & $2.48(0.09)$ & $2.51(0.10)$ & $2.53(0.08)$ & $2.35(0.06)$ & $2.24(0.05)$ \\
\hline CESO & $1.04(0.00)$ & - & $1.38(0.02)$ & $1.72(0.02)$ & $1.24(0.01)$ & $1.45(0.01)$ & $1.28(0.02)$ & - \\
\hline rSPSO & $1.42(0.06)$ & $1.04(0.03)$ & $1.50(0.08)$ & $2.20(0.07)$ & $2.62(0.07)$ & $2.72(0.08)$ & $2.93(0.06)$ & $2.79(0.05)$ \\
\hline SPSO & $2.64(0.10)$ & $2.15(0.07)$ & $2.51(0.09)$ & $3.21(0.07)$ & $3.64(0.07)$ & $3.86(0.08)$ & $4.01(0.07)$ & $3.82(0.05)$ \\
\hline AmQSO & $2.62(0.10)$ & $1.01(0.09)$ & $1.51(0.10)$ & $2.00(0.15)$ & $2.19(0.17)$ & $2.43(0.13)$ & $2.68(0.12)$ & $2.62(0.10)$ \\
\hline mPSO & $2.42(0.05)$ & $1.82(0.08)$ & $1.85(0.08)$ & $2.48(0.09)$ & $2.51(0.10)$ & $2.53(0.08)$ & $2.35(0.06)$ & $2.24(0.05)$ \\
\hline APSO & $0.53(0.01)$ & $1.05(0.06)$ & $1.31(0.03)$ & $1.69(0.05)$ & $1.78(0.02)$ & $1.95(0.02)$ & $1.95(0.01)$ & $1.90(0.01)$ \\
\hline IMMPSO & $0.18(0.01)$ & $0.47(0.05)$ & $0.67(0.04)$ & $0.93(0.04)$ & $1.14(0.04)$ & $1.32(0.04)$ & $1.61(0.03)$ & $1.67(0.03)$ \\
\hline SFA & $0.42(0.03)$ & $0.89(0.07)$ & $1.05(0.04)$ & $1.48(0.05)$ & $1.56(0.06)$ & $1.87(0.05)$ & $2.01(0.04)$ & $1.99(0.06)$ \\
\hline PSO- $\Lambda Q$ & $0.34(0.02)$ & $0.80(0.12)$ & $0.89(0.03)$ & $1.45(0.06)$ & $1.52(0.04)$ & $1.77(0.05)$ & $1.95(0.05)$ & $1.96(0.04)$ \\
\hline CDEPSO & $0.41(0.00)$ & $0.97(0.01)$ & $1.22(0.01)$ & $1.54(0.01)$ & $2.62(0.01)$ & $2.20(0.01)$ & $1.54(0.01)$ & $2.11(0.01)$ \\
\hline CbDE-wCA & $0.14(0.03)$ & $\mathbf{0 . 3 0 ( 0 . 0 2 )}$ & $0.86(0.08)$ & $0.98(0.05)$ & $1.34(0.04)$ & $1.31(0.04)$ & $1.35(0.03)$ & $1.29(0.02)$ \\
\hline WD2O & $1.21(0.03)$ & $0.76(0.003)$ & $1.25(0.02)$ & $1.22(0.01)$ & $1.75(0.01)$ & $1.87(0.01)$ & $2.10(0.01)$ & $1.95(0.01)$ \\
\hline cGA & $0.92(0.09)$ & $1.06(0.07)$ & $1.15(0.10)$ & $1.18(0.06)$ & $1.35(0.51)$ & $1.65(0.07)$ & $1.80(0.06)$ & $1.71(0.05)$ \\
\hline BfCS-wVN & $0.30(0.06)$ & $0.38(0.21)$ & $\mathbf{0 . 5 1 ( 0 . 1 1 )}$ & $\mathbf{0 . 7 4 ( 0 . 1 2 )}$ & $1.00(0.11)$ & $0.84(0.06)$ & $1.11(0.06)$ & $1.18(0.08)$ \\
\hline idPSO & $0.12(0.02) \mathrm{e}-7$ & $0.58(0.07)$ & $0.62(0.05)$ & $0.75(0.03)$ & $0.67(0.04)$ & $0.64(0.01)$ & $0.25(0.02)$ & $0.26(0.04)$ \\
\hline
\end{tabular}

است كه مقدار فركانس كمتر يعنى زمان بهمراتب كمتر براى وفق يافتن با محيط جديد و در طرف مقابل فرصت مناسب براى يافتن و بهبون بهترين بجينه متناظر با مقدار فركانس بالا

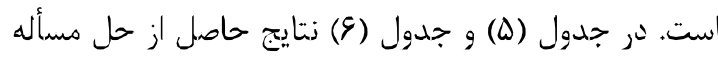

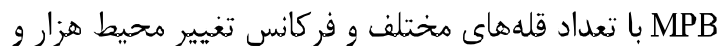

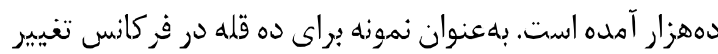

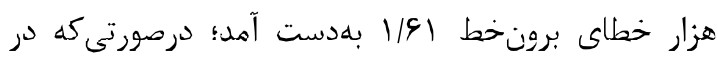

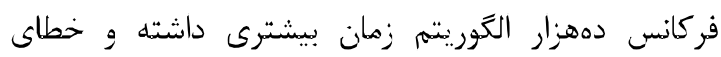
برون خط تا سش/ • كاهش مى يابد.

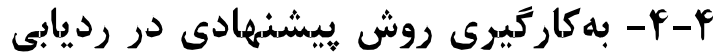 هدف متحرك}

يكى از كاربرهاى روش بيشنهادى در رديابى هدف در فيلمم

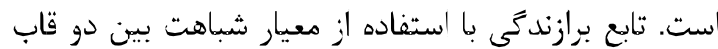

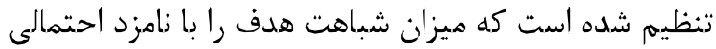

(جدول - f): مقايسه خطاى برون خط الكَوريتهمها براى مقادير

مختلف shift severity در مسأله

(Table-4): Comparison of the offline crror of algorithms for various shift Severity in MPB problem

\begin{tabular}{|c|c|c|c|c|}
\hline \multirow{2}{*}{ Nlgorithm } & \multicolumn{4}{|c|}{ Shift severity, $s$} \\
\cline { 2 - 5 } & 1 & 2 & 3 & 5 \\
\hline CPSO & $\mathbf{1 . 0 6 ( 0 . 2 4 )}$ & $1.17(0.22)$ & $1.36(0.28)$ & $1.58(0.32)$ \\
\hline mCPSO & $2.05(0.07)$ & $2.80(0.07)$ & $3.57(0.08)$ & $4.89(0.11)$ \\
\hline mQSO(5,5q) & $1.85(0.08)$ & $2.40(0.06)$ & $3.00(0.06)$ & $4.24(0.10)$ \\
\hline CESO & $1.38(0.02)$ & $1.78(0.02)$ & $2.03(0.03)$ & $2.52(0.06)$ \\
\hline rSPSO & $\mathbf{1 . 5 0 ( 0 . 0 8 )}$ & $1.87(0.05)$ & $2.40(0.08)$ & $3.25(0.09)$ \\
\hline SPSO & $2.51(0.09)$ & $3.78(0.09)$ & $4.96(0.12)$ & $6.76(0.15)$ \\
\hline cGA & $0.92(0.09)$ & $2.19(0.15)$ & $3.31(0.25)$ & $6.45(0.45)$ \\
\hline BfCS-wVN & $\mathbf{0 . 5 1 ( 0 . 1 1 )}$ & $0.89(0.16)$ & $1.26(0.13)$ & $2.39(0.20)$ \\
\hline idPSO & $0.62(0.05)$ & $0.67(0.07)$ & $\mathbf{0 . 7 6 ( 0 . 0 6 )}$ & $0.91(0.09)$ \\
\hline
\end{tabular}

\section{r. تغييير فركاتس تغبييرات محيط:}

فركانس تغيير محيط Uل درواقع زمان الحوريتم براى يافتن بهينه در هر هحيط قبل از تغيير را مشخص مى مند. واضح

${ }^{1}$ shift severity 


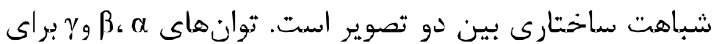

تنظيهم اثر هر معيار روى هقدار يايانى شباهت استفاده شده

$\alpha \cdot \beta . \gamma \geq 0$

معيار شباهت تعريفشده در معادله (9) يك مرز بالايى

يكتايى دارد: SIM(a,b) . SIM(a,b)=1

$$
\text { كرفتت شده است. }
$$

ديده مىشود، الكوريتم

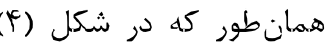

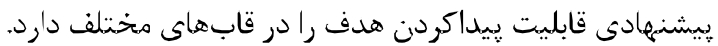
در اين ويدئو فاصله بين قابها ينج قاب در نظر كرفته شده

است تا حركت هدف در تصوير هحسوس باشد.
اندازه كيرى مى كند و بيشترين شباهت را بهعنوان محل هدف

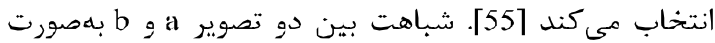

زير تعريف مىشود:

$\operatorname{SIM}(\mathrm{a} \cdot \mathrm{b})=\left(\frac{2 \mu_{\mathrm{a}} \mu_{\mathrm{a}}}{\mu_{\mathrm{a}}^{2}+\mu_{\mathrm{b}}^{2}}\right)^{\alpha}\left(\frac{2 \sigma_{\mathrm{a}} \sigma_{\mathrm{b}}}{\sigma_{\mathrm{a}}^{2}+\sigma_{\mathrm{b}}^{2}}\right)^{\beta}\left(\frac{\sigma_{\mathrm{ab}}}{\sigma_{a} \sigma_{\mathrm{b}}}\right)^{\gamma}$

$\mu_{a}=\frac{1}{N} \sum_{i=1}^{N} a_{i}$

كه در آن $\mu$ ميانگين:

$\sigma_{a}=\left(\frac{1}{N-1} \sum_{i=1}^{N}\left(a_{i}-\mu_{a}\right)^{2}\right)^{\frac{1}{2}}$

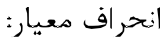

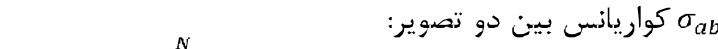

$\sigma_{a b}=\frac{1}{N-1} \sum_{i=1}^{N}\left(a_{i}-\mu_{a}\right)\left(b_{i}-\mu_{b}\right)$

سه مؤلفه شباهت از جِّ، دعيار نزديكى روشنايى، وضوح و
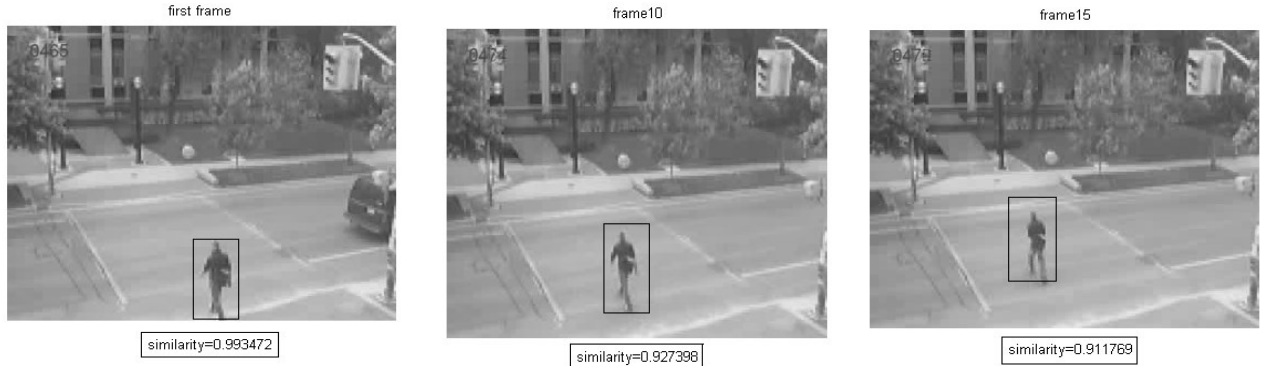

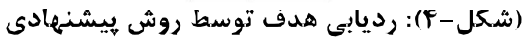

(Figure-4): Target tracking by the proposed method

U = 1000 (جدول -ه): مقايسه خطاى آفلاين الكوريتمها براى تعداد قله هاى متفاوت در مسأله

(Table-5): Comparison of offline crror algorithms for different peak numbers in the MPB problem at the change frequency of $U=1000$

\begin{tabular}{|c|c|c|c|c|c|c|c|c|}
\hline \multirow{2}{*}{ Algorithm } & \multicolumn{8}{|c|}{ Number of peaks, $p$} \\
\hline & 1 & 5 & 10 & 20 & 30 & 50 & 100 & 200 \\
\hline AmQSO & $2.33(0.31)$ & $2.90(0.32)$ & $4.56(0.40)$ & $5.36(0.47)$ & $5.20(0.38)$ & $6.06(0.14)$ & $4.77(0.45)$ & $5.75(0.26)$ \\
\hline APSO & $2.72(0.04)$ & $2.99(0.09)$ & $3.87(0.08)$ & $4.13(0.06)$ & $4.12(0.04)$ & $4.11(0.03)$ & $4.26(0.04)$ & $4.21(0.02)$ \\
\hline FTMPSO & $0.89(0.05)$ & $1.70(0.10)$ & $2.36(0.09)$ & $3.01(0.12)$ & $3.06(0.10)$ & $3.29(0.10)$ & $3.63(0.09)$ & $3.74(0.09)$ \\
\hline SFA & $2.45(0.12)$ & $2.71(0.06)$ & $3.64(0.04)$ & $4.01(0.07)$ & $4.02(0.08)$ & $4.12(0.07)$ & $4.40(0.07)$ & $4.43(0.07)$ \\
\hline
\end{tabular}

(جدول - (9): مقايسه خطاى آفلاين الكوريتمها براى تعداد قله هاى متغاوت در مسأله MPB در فركانس تغييرات

(Table-6): Comparison of offline error algorithms for different peak numbers in the MPB problem at the change frequency of $U=10000$

\begin{tabular}{|c|c|c|c|c|c|c|c|c|}
\hline \multirow{2}{*}{ Algorithm } & \multicolumn{8}{|c|}{ Number of peaks, $p$} \\
\cline { 2 - 9 } & 1 & 5 & 10 & 20 & 30 & 50 & 100 & 200 \\
\hline mQSO(5,5q) & $1.90(0.18)$ & $1.03(0.06)$ & $\mathbf{1 . 1 0 ( 0 . 0 7 )}$ & $1.84(0.09)$ & $2.00(0.09)$ & $1.99(0.07)$ & $1.85(0.05)$ & $1.71(0.04)$ \\
\hline $\mathbf{A m Q S O}$ & $0.19(0.02)$ & $0.45(0.04)$ & $0.76(0.06)$ & $1.28(0.12)$ & $1.78(0.09)$ & $1.55(0.08)$ & $1.89(0.14)$ & $2.52(0.10)$ \\
\hline mPSO & $0.27(0.02)$ & $0.70(0.10)$ & $0.97(0.04)$ & $1.34(0.08)$ & $1.43(0.05)$ & $\mathbf{1 . 4 7 ( 0 . 0 4 )}$ & $1.50(0.03)$ & $1.48(0.02)$ \\
\hline APSO & $0.25(0.01)$ & $0.57(0.03)$ & $0.82(0.02)$ & $1.23(0.02)$ & $1.39(0.02)$ & $1.46(0.01)$ & $1.38(0.01)$ & $1.36(0.01)$ \\
\hline FTMPSO & $0.09(0.00)$ & $0.31(0.04)$ & $0.43(0.03)$ & $0.56(0.01)$ & $0.69(0.09)$ & $0.86(0.02)$ & $1.08(0.03)$ & $1.13(0.04)$ \\
SFA & $0.26(0.03)$ & $0.53(0.04)$ & $0.72(0.02)$ & $0.91(0.03)$ & $0.99(0.04)$ & $1.19(0.04)$ & $1.44(0.04)$ & $1.52(0.03)$ \\
\hline BCCS-wVN & $0.18(0.04)$ & $0.20(0.02)$ & $\mathbf{0 . 3 0 ( 0 . 0 6 )}$ & $0.84(0.05)$ & $0.66(0.08)$ & $0.54(0.70)$ & $0.85(0.05)$ & $0.85(0.05)$ \\
\hline idPSO & $0.3(0.04) \mathrm{e}-12$ & $0.12(0.03)$ & $0.33(0.04)$ & $0.44(0.07)$ & $0.53(0.10)$ & $0.43(0.05)$ & $0.19(0.00)$ & $0.19(0.00)$ \\
\hline
\end{tabular}

$T_{1}=$ O(FreePartc + FocusPartc $)$

متهركز (FocusPartc)

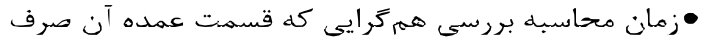

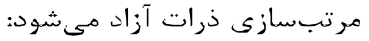

$T_{2}=O(\log ($ FreePartc $))$

•زمان محاسبة بررسى همايوشانى مراكز (FSZ)

$T_{3}=O(\log ($ FocusPartc $))$

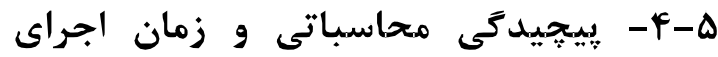
الخَوريتم

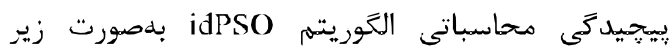
هحاسبه مى شون:

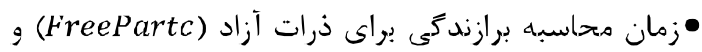


دليل سازوكار كوتاه و مختصر خود سرعت مناسبى براى

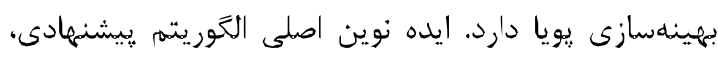
انطباق هميشكى تعداد ذرات با شرايط محيطى براى يافتن و

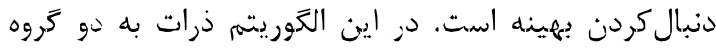

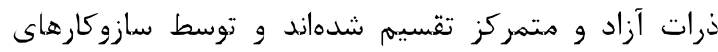
نوينى روند ايجاد و حذف ذرات متهركز كنترل مىشون. همجنين الكوريتم idPSO به كونهاى طراحى شده است كه نياز

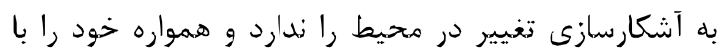
شرايط دحيط وقف هى بهد. در بهينهسازى يويا كاستن از زمان بهينهسازى بهعبارت ديخر همركرايى سريعتر به بهينه در عين حفظ تنوع

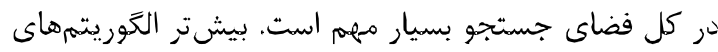

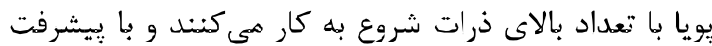
روند بهينهسازى از تعداد ذرات كاسته مىشود. اين قضيه به هعناى صرف زمان بيهوده براى محاسبه بر زازند تى تعداد ذرات اترات

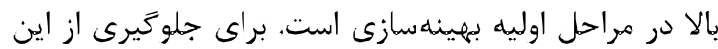

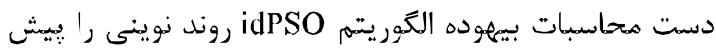
كرفته است و با ذرات كم شروع به كار مى كند و همواره افزايش تعداد ذرات تابع شرايط هحيط ازجمله افزايش تعداد

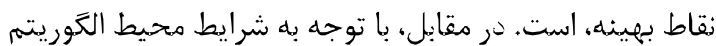
اقدام به كاهش تعداد ذرات كرنه كه خود سبب كاهش بار محاسباتى و افزايش سرعت بهينهسازى مى شود.

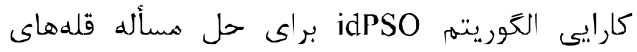
متحرك (MPB) كه يكى از معروفترين توابع محكى در

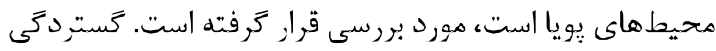
آزمايشها براى تنظيمهاى مختلف مسأله MPB اعم از تعداد

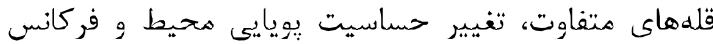
تغيير هحيط متفاوت، نشان از عملكرد مناسب الكوريته بِيشنهادى در مقايسه با ساير الكوريتهماى هطرح در زمينه

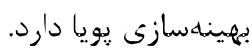
از جمله بيشنهادهاى يزوهشهاى آينده مىتوان به به كاركيرى الكوريتهم براى بهينهازئ مسائل واقعى دنيا، اشاره كرد. همجنين بهكار كيرى الگَوريتم در خوشهيابى' يويا هانند

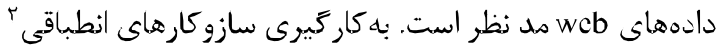

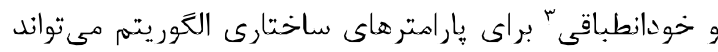

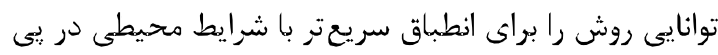

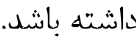

${ }^{1}$ Clustering

${ }^{2}$ Adaptive

${ }^{3}$ Self adaptive
•زمان مورد نياز براى تشخيص و حذف FSZ هاى اضافى كه صرف مرتبسازى برازندگى مراكز FSZ ها و مقايسه با بال $T_{4}=O\left(\log (\right.$ FocusPartc) $)$ مى $P_{\text {mean }}$ קيججيدگى دحاسباتى الكوريتم پِيشنهادى بهصورت محاسبه مىشود. درصورتى $T_{\text {total }}=T_{1}+T_{2}+T_{3}+T_{4}$ كه M را مجموع كل ذرات در نظر بكيريم مرتبه بيجيدكى الكوريتم ريشنهادى بلهورت در جدول (V) الكوريتم idPSO با سه الكوريتم CPSO،

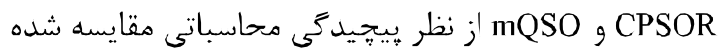
است (مقدار M اندازه جمعيت در الكوريتهمها است).

(جدول) (

(Table-7): Comparison of Computation Complexity

\begin{tabular}{|c|c|}
\hline Algorithm & Computation Complexity \\
\hline CPSO & $O\left(M^{3}\right)$ \\
\hline CPSOR & $O\left(M^{3}\right)$ \\
\hline mQSO $(5,5 \mathrm{q})$ & $O\left(M^{2}\right)$ \\
\hline idPSO & $O(M)$ \\
\hline
\end{tabular}

در شكل (ه) زمان اجراى التوريته بيشنهادى آورده

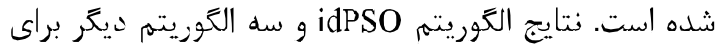
يكبار تغيير در محيط بنجزبعدى و تعداد قله ده در فركانس

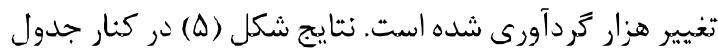

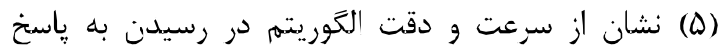

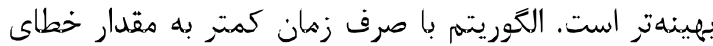
برون خط بهترى نسبت ساير الخَوريتمها دست يافته است.

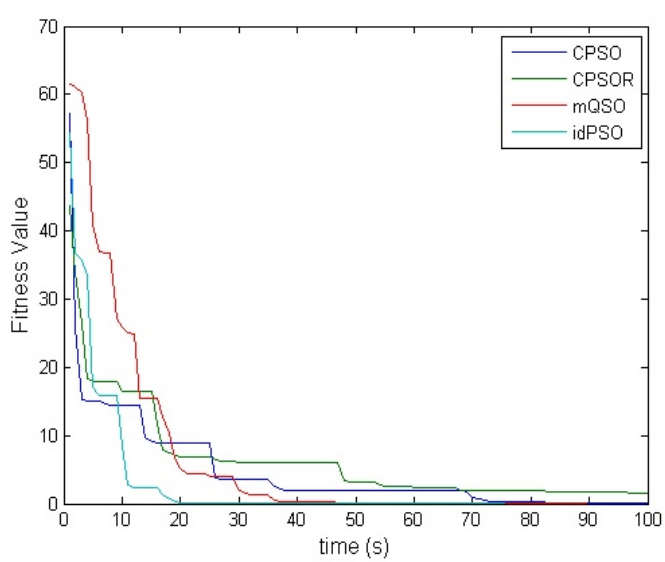

MPB شكل - ه): مقايسه زمان اجراى العوريتمها براى مسأله (Figure-5): Comparison of run time algorithms for the MPB problem

\section{ه- نتيجه كيرى و بحث}

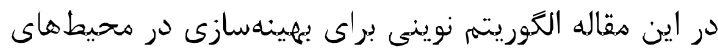

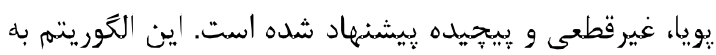


Computational Intelligence in Dynamic and Uncertain Environments (CIDUE), pp. 9-16, 2014.

[12] B. van Veen, M. Emmerich, Z. Yang, T. B"ack, J. Kok, "Ant colony algorithms for the dynamic vehicle routing problem with time windows", in J. M. Ferr'andez Vicente, J. R. 'Alvarez S'anchez, F. de la Paz L'opez, F. J. Toledo Moreo (Eds.), Natural and Artificial Computation in Enginecring and Medical Applications: 5th International Work-Conference on the Interplay Between Natural and Artificial Computation, IWINAC 2013, Mallorca, Spain, Proceedings, Part II, Springer Berlin Heidelberg, Berlin, Heidelberg, 2013, pp. 1-10.

[13] Z. Yang, M. Emmerich, T. B"ack, "Ant based solver for dynamic vehicle routing problem with time windows and multiple priorities", in 2015 IEEE Congress on Evolutionary Computation (CEC), 2015, pp. 2813-2819.

[14] L. Melo, F. Pcrcira, E. Costa, "Multi-caste ant colony algorithm for the dynamic traveling salesperson problem", in M. Tomassini, A. Antonioni, F. Daolio, P. Buesser (Eds.), Adaptive and Natural Computing Algorithms, Vol. 7824 of Lecture Notes in Computer Science, Springer Berlin IIcidelberg, 2013, pp. 179188.

[15] L. Melo, F. Pereira, E. Costa, "Extended experiments with ant colony optimization with heterogeneous ants for large dynamic traveling salesperson problems", in 14th International Conference on Computational Science and Its Applications (ICCSA), 2014, pp. 171-175.

[16] U. Boryczka, Ł. Stra,k, "IIcterogeneous DPSO algorithm for DTSP", in M. N'ũnez, T. N. Nguyen, D. Camacho, B. Trawi 'nski (Eds.), Computational Collective Intelligence: 7th International Conference, ICCCI 2015, Madrid, Spain, Proceedings, Part II, Springer International Publishing, Cham, 2015, pp. 119128.

[17] M. Okulewicz, J. Ma'ndziuk, "Two-phase multiswarm PSO and the dynamic vehicle routing problem", in IEEE Symposium on Computational Intelligence for Human-like Intelligence (CIIILI), pp. 1-8, 2014

[18] M. Mavrovouniotis, S. Yang, "Dynamic vehicle routing: A memetic ant colony optimization approach", in A. Uyar, E. Ozcan, N. Urquhart (Eds.), Automated Scheduling and Planning, Vol. 505 of Studies in Computational Intelligence, Springer Berlin IIcidelberg, 2013, pp. 283301.

[19] M. Mavrovouniotis, F. M. M“uller, S. Yang, "Ant colony optimization with local search for the dynamic travelling salesman problems", IEEE Trans. Cybern, Vol. 99, pp. 1-14, 2016.

[20] L. Liu and S. R. Ranjithan, " $\Lambda$ n adaptive optimization technique for dynamic envir-

\section{6- References}

[1] M. Mavrovouniotis, Ch. Li and S. Yang, "A survey of swarm intelligence for dynamic optimization: Algorithm and application", Swarm and Evolutionary Computation, Vol. 33, pp. 1-17, 2017.

[2] T. T. Nguyen, S. Yang, and J. Branke, "Evolutionary dynamic optimization: A survey of the state of the art", Swarm and Evolutionary Computation, Vol. 6, pp. 1-24, 2012.

[3] J. Euchi, A. Yassine, H. Chabchoub, “The dynamic vehicle routing problem: Solution with hybrid metaheuristic approach", Swarm and Evol. Comput, Vol. 21, pp. 41-53, 2015.

[4] Y. E. Demirtas „, E. “Ozdemir, U. Demirtas,, "A particle swarm optimization for the dynamic vehicle routing problem", in Modeling, Simulation, and Applied Optimization (ICMSAO), 6th International Conference on, 2015, pp. 1-5.

[5] M. Mavrovouniotis, S. Yang, "Applying ant colony optimization to dynamic binary-encoded problem", in A. Mora, G. Squillero (Eds.), EvoApplications: $\Lambda$ pplications of Evolutionary Computation, Vol. 9028 of Lecture Notes in Computer Science, Springer International Publishing, 2015, pp. 845-856.

「6] U. Boryczka, Ł. Stra,k, "Diversification and entropy improvement on the DPSO algorithm for DTSP", in T. N. Nguyen, B. Trawi 'nski, R. Kosala (Eds.), Intelligent Information and Database Systcms: 7th Asian Conference, ACIIDS 2015, Bali, Indonesia, Proceedings, Part I, Springer International Publishing, Cham, 2015, pp. 337-347.

[7] M.Mavrovouniotis, S. Yang, "Ant colony optimization with self-adaptive evaporation rate in dynamic environments", in IEEE Symposium on Computational Intelligence in Dynamic and Uncertain Environments (CIDUE), pp. 47-54, 2014.

[8] S. Gao, Y. Wang, J. Cheng, Y. Inazumi, Z. Tang, "Ant colony optimization with clustering for solving the dynamic location routing problem", $\Lambda$ ppl. Math. Comput., Vol. 285, pp. 149 173, 2016.

[9] M. Mavrovouniotis, S. Yang, "Ant colony optimization with memorybased immigrants for the dynamic vehicle routing problem", in 2012 IEEE Congress on Evolutionary Computation (CEC), pp. 2645-2652, 2012.

[10] M. Mavrovouniotis, S. Yang, "Ant colony optimization with immigrants schemes for the dynamic travelling salesman problem with traffic factors", Appl. Soft Comput., Vol. 13, pp. 4023 4037, 2013.

[11] M. Mavrovouniotis, S. Yang, X. Yao, "Multicolony ant algorithms for the dynamic travelling salesman problem", in IEEE Symposium on 
[32]T. M. Blackwell and J. Branke, "Multiswarms, exclusion, and anticonvergence in dynamic environments", LEEE Trans. Evol. Comput., Vol. 10, No. 4, pp. 459 472, 2006.

[33]I. del $\Lambda$ mo, D. Pelta, Gonz'aez, and J. lez, "Using heuristic rules to enhance a multiswarm pso for dynamic environments", in 2010 Congr. Evol. Comput., 2010, pp. 1-8.

[34] D. Yazdani, B. Nasiri, A. Sepas-Moghaddam, and M. R. Meybodi, "A novel multi-swarm algorithm for optimization in dynamic environments based on particle swarm optimization", Applied Soft Computing, Vol. 13, pp. 2144-2158, 2013.

[35] A. Boulesnane, S. Meshoul, "WD2O: a novel wind driven dynamic optimization approach with effective change detection," Applied Intelligence, Vol. 47, pp. 488 504, September 2017.

[36] J. Kazemi Kordestani, H. Abedi Firouzjaee, M. R. Meybodi, "An adaptive bi-flight cuckoo search with variable nests for continuous dynamic optimization problems," Applied Intelligence, Vol. 48, pp. 97-117, January 2018.

[37] N. Fouladgar, S. Lotfi, "A novel approach for optimization in dynamic environments based on modified cuckoo search algorithm," Soft Comput, pp 1-15, 2015.

[38] C. Li, S. Yang, “A general framework of multipopulation methods with clustering in undetectable dynamic environments", IEEE Trans. Evol. Comput, Vol. 16, No. 4, pp. 556-577, 2012.

「39†R. I. Lung and D. Dumitrescu, "Evolutionary swarm cooperative optimization in dynamic environments", Natural Comput., Nol. 9, No. 1, pp. 83-94, 2010.

[40]H. Richter, "Detecting change in dynamic fitness landscapes", in 2009 Congr. Evol. Comput., 2009, pp. 1613-1620.

[41] A. Simoes and E. Costa, "Evolutionary algorithms for dynamic environments: prediction using linear regression and markov chains", in Parallel Problem Solving from Nature, pp. $306315,2008$.

[42] R. C. Eberhart and J. Kennedy, "A new optimizer using particle swarm theory", in Proc. 6th Int. Symp. Micro Mach. Human Sci., 1995, pp. 39-43.

[43] J. Kennedy and R. C. Eberhart, "Particle swarm optimization", in Proc. IEEE Int. Conf. Neural Netw., 1995, pp. 1942-1948. onments", Eng. Appl. Artif. Intell., Vol. 23, No. 5, pp. 772 779, 2010.

[21]D. Parrott and X. Li, "Locating and tracking multiple dynamic optima by a particle swarm model using speciation", IEEE Trans. Evol. Comput., Vol. 10, No. 4, pp. 440-458, 2006.

[22] S. Yang and C. Li, "A clustering particle swarm optimizer for locating and tracking multiple optima in dynamic environments ", IEEE Trans. Evol. Comput., Vol. 14, No. 6, pp. 959 974, 2010 .

[23] C. Li and S. Yang, "A clustering particle swarm optimizer for dynamic optimization", in Congr. Evol. Comput., pp. 439-446, 2009.

[24]J. Branke, The Moving Peaks Benchmark, 1999.Available:http:/web.archive.org/web/2 0130906140931/http:/pcoplc.ailb.kit.cdu/jbr/ MovPeaks/

[25] J. Branke, "Memory enhanced evolutionary algorithms for changing optimization problems", in Congr. Evol. Comput., Vol. 3, 1999 , pp. 1875-1882.

「26]J. Yaochu and J. Branke, "Evolutionary optimization in uncertain environments-a survey", IEEE Transactions on Evolutionary Computation, Vol. 9, pp. 303-317, 2005.

[27] M. Khouadjia, E. Alba, L. Jourdan, E.-G. Talbi, "Multi-swarm optimization for dynamic combinatorial problems: A case study on dynamic vehicle routing problem", in $\mathrm{M}$. Dorigo, M. Birattari, G. Di Caro, R. Doursat, A. Engelbrecht, D. Florcano, L. Gambardella, R. Groß, E. S, ahin, H. Sayama, T. St "utzle (Eds.), Swarm Intelligence, Vol. 6234 of Lecture Notes in Computer Science, Springer Berlin Heidelberg, 2010, pp. 227-238.

[28] J. Branke, T. Kaußler, C. Schmidth, and H. Schmeck, "A multipopulation approach to dynamic optimization problem", in 4th Int. Conf. Adaptive Comput. Des. Manuf., 2000 pp. 299308.

[29] C. Li and S. Yang, "Fast multi-swarm optimization for dynamic optimization problems", in 4th Int. Conf. Natural Comput., Vol. 7, 2008, pp. 624628.

[30]M. Kamosi, A. B. Hashemi, and M. R. Meybodi, "A hibernating multiswarm optimization algorithm for dynamic environments", in World Congr. on Nature and Biologically Inspired Computing, NaBIC2010, 2010, pp. 363-369.

[31] T. M. Blackwell and J. Branke, "Multi-swarm optimization in dynamic environments", in EvoWorkshops 2004: Appl. Evol. Comput., LNCS 3005, 2004, pp. 489-500. 


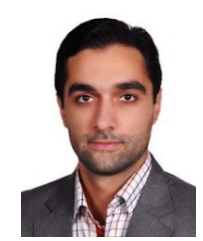

سيدمسعود اجابتى دوره كارشناسى و

كارشناسى ارشد خوف را در رشته مهندسى

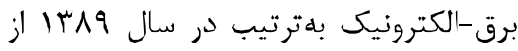

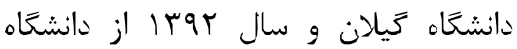

بيرجند اخذ كرده و در حال حاضر نيز

دانشجوى دكتراى مهندسى برق -الكترونيك دانشعاه بيرجند

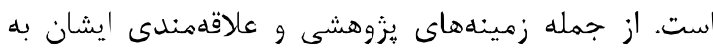

بازشناسى الخو، بهينهسازى يويا، الخوريتهمهاى تكاملى و ودينى

يردازش سيخنال مىتوان اشاره كرد.

نشانى رايانامه ايشان عبارت است ازئ لرون

cjabati_masoud@birjand.ac.ir

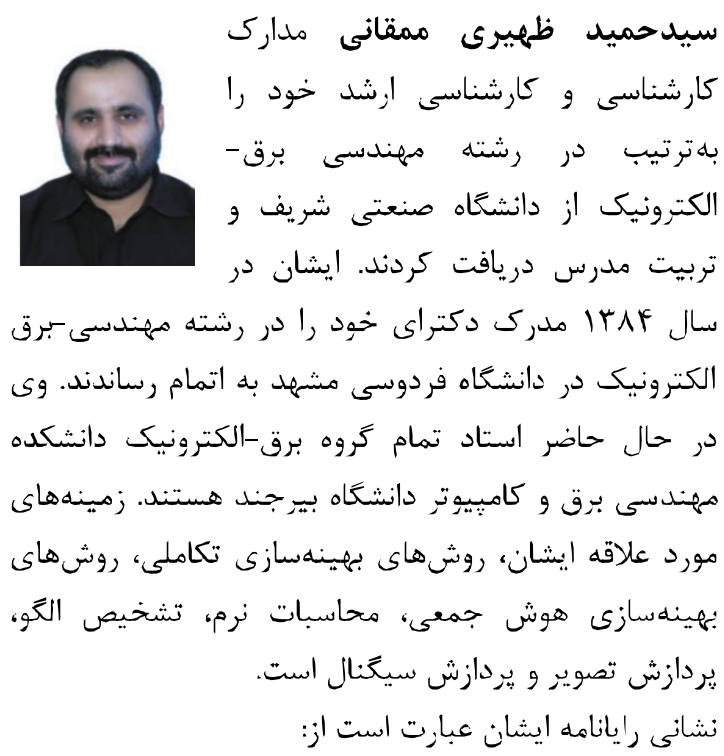

hzahiri@birjand.ac.ir
44|Y. Shi, R. Eberhart, "A modified particle swarm optimizer", in Proc. IEEE Conf. Evol. Comput., 1998, pp. 69-73.

[45]R. I. Lung and D. Dumitrescu, "A collaborative model for tracking optima in dynamic environments", in Proc. Congr. Evol. Comput., 2007, pp. 564-567.

[46] S. Bird and X. Li, "Using regression to improve local convergence", in Proc. IEEE Congr. Evol. Comput., 2007, pp. 592-599.

[47] T. Blackwell, J. Branke, and X. Li, "Particle swarms for dynamic optimization problems", Swarm Intelligence, pp. 193-217, 2008.

[48] M. Kamosi, A. Hashemi, and M. Meybodi, "A New Particle Swarm Optimization Algorithm for Dynamic Environments", Swarm Evolutionary and Memetic Com-puting, pp. 129-138, 2010.

[49] I. Rezazadeh, M. Meybodi, and A. Naebi, " $\Lambda$ daptive particle swarm optimization algorithm for dynamic environments", $A d$-vances in Swarm Intelligence, pp. 120-129, 2011.

[50] B. Nasiri and M. Meybodi, "Speciation based firefly algorithm for optimization in dynamic environments", International Journal of Artificial Intelligence, Vol. 8, pp. 118-132, 2012.

[51] D. Yazdani, B. Nasiri, R. Azizi, A. SepasMoghaddam, and M. R. Mcybodi, "Optimization in Dynamic Environments Utilizing a Novel Method Based on Particle Swarm Optimization", International Journal of Artificial Intelligence, Vol. 11, pp. 170-192, 2013.

[52]J. K. Kordestani, A. Rezvanian, and M. R. Meybodi, "CDEPSO: a bi-population hybrid approach for dynamic optimization problcms", Applied intelligence, Vol. 40, pp. 682694, 2014.

[53] R. Mukherjee, G. R. Patra, R. Kundu, and S. Das, "Cluster-based differential evolution with Crowding Archive for niching in $\mathrm{dy}$ namic environments", Information Sciences, Vol. 267, pp. 58- 82, 2014.

[54] M. Mohammadpour, H. Parvin, M. Sina, "Chaotic Genetic Algorithm based on Explicit Memory with a new Strategy for Updating and Retrieval of Memory in Dynamic Environments," AI and Data Mining, Vol. 6, pp. 191-205, Winter and Spring 2018.

[55] E. Wang, 7. Bovik, A. Sheik, H. Simoncelli, "Image quality assessment: from error visibility to structural similarity", IEEE Transactions on Image processing, 2004. 
